\title{
openheart Bias associated with left ventricular quantification by multimodality imaging: a systematic review and meta-analysis
}

\author{
Marzia Rigolli, ${ }^{1,2}$ Sulakchanan Anandabaskaran, ${ }^{1}$ Jonathan P Christiansen, ${ }^{1}$ \\ Gillian A Whalley ${ }^{1,3}$
}

To cite: Rigolli M, Anandabaskaran $\mathrm{S}$, Christiansen JP, et al. Bias associated with left ventricular quantification by multimodality imaging: a systematic review and meta-analysis. Open Heart 2016;3:e000388. doi:10.1136/openhrt-2015000388

- Additional material is available. To view please visit the journal online (http://dx. doi.org/10.1136/openhrt2015-000388)

\section{MR and SA were equal} contributors to this manuscript and are co-first authors.

This author, Dr Whalley, takes responsibility for all aspects of the reliability and freedom from bias of the data presented and their discussed interpretation.

Received 15 December 2015 Revised 9 March 2016 Accepted 15 March 2016

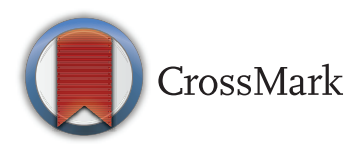

For numbered affiliations see end of article.

Correspondence to Dr Gillian A Whalley; gillianwhalleyphd@gmail.com

\section{ABSTRACT}

Purpose: Cardiac MR (CMR) is the gold standard for left ventricular (LV) quantification. However, twodimensional echocardiography (2DE) is the most common approach, and both three-dimensional echocardiography (3DE) and multidetector CT (MDCT) are increasingly available. The clinical significance and interchangeability of these modalities remains underinvestigated. Therefore, we undertook a systemic review to evaluate the accuracy and absolute bias in LV quantification of all the commonly available noninvasive imaging modalities (2DE, CE-2DE, 3DE, MDCT) compared to cardiac MR (CMR).

Methods: Studies were included that reported LV echocardiographic (2DE, CE-2DE, 3DE) and/or MDCT measurements compared to CMR. Only modern CMR (SSFP sequences) was considered. Studies involving small sample size (<10 patients) and unusual cardiac geometry (ie, congenital heart diseases) were excluded. We evaluated LV end-diastolic volume (LVEDV), endsystolic volume (LVESV) and ejection fraction (LVEF). Results: 1604 articles were initially considered: 65 studies were included (total of 4032 scans (echo, CT, MRI) performed in 2888 patients). Compared to CMR, significant biased underestimation of LV volumes with 2DE was seen (LVEDV-33.30 mL, LVESV $-16.20 \mathrm{~mL}$, $p<0.0001)$. This difference was reduced but remained significant with CE-2DE (LVEDV -18.05, $p<0.0001)$ and 3DE (LVEDV -14.41, $p<0.001)$, while MDCT values were similar to CMR (LVEDV $-1.20, p=0.43$; LVESV $-0.13, p=0.91)$. However, excellent agreement for echocardiographic LVEF evaluation (2DE LVEF $0.78-1.01 \%, p=0.37$ ) was observed, especially with 3DE (LVEF 0.14\%, $p=0.88$ ).

Conclusions: Comparing imaging modalities to CMR as reference standard, 3DE had the highest accuracy in LVEF estimation: 2DE and 3DE-derived LV volumes were significantly underestimated. Newer generation CT showed excellent accuracy for LV volumes.

\section{INTRODUCTION}

In the modern era of cardiovascular multimodality imaging, accurate assessment of

\section{KEY QUESTIONS}

What is already known about this subject?

- Anecdotally, clinicians understand that different imaging methods give different results. For example, echo is known to underestimate LV volumes compared with MRI and these differences are ameliorated with the addition of contrast or $3 \mathrm{D}$ echo.

What does this study add?

- This study compares all imaging modalities to provide an overall picture of the differences that might be anticipated. Previous studies have evaluated and presented the bias (in percentage units) between echo and MRI, but not the actual values. A unique feature of this meta-analysis is that bias is presented in terms of millilitres (for volumes) and percentage points for ejection fraction; values that translate into clinical practice easily.

How might this impact on clinical practice?

- Increasingly, multi-modality imaging is being used to determine left ventricular volumes and ejection fraction. Since these measurements are essential components of clinical management, understanding the anticipated differences that may arise due to different imaging techniques alone, and differentiating these from potential clinical changes, is a key component of clinical management.

left ventricular (LV) function is of paramount importance: LV volumes and ejection fraction (LVEF) are crucial parameters in clinical decision-making, diagnosis and outcome and are included in the main guidelines and trials. ${ }^{1-5}$ The absolute LV parameters, derived from imaging, and their variation over time, are used to guide surgical timing, device implantation and medical therapy introduction. ${ }^{1}{ }^{2}$ Although several imaging methods are widely available for $\mathrm{LV}$ quantification, cardiac MR (CMR) is considered the most accurate modality and is recognised as the gold standard. ${ }^{6}$ Nevertheless, non-contrast two-dimensional echocardiography (2DE) is still the most 
widespread method used in clinical practice, mainly due to feasibility, wide distribution and rapid acquisition. ${ }^{7}$ However, 2DE has several intrinsic weaknesses, it is: user-dependent; affected by geometrical assumptions; often subject to foreshortening and limited by poor endocardial definition. By reducing these limitations, three-dimensional echocardiography (3DE) has been reported as a more reproducible and accurate modality for LV volume assessment. ${ }^{8-10}$ In addition, multidetector CT (MDCT) is increasingly available for its clinical applications and as a possible alternative in those patients for whom echocardiography may be unreliable or CMR contraindicated. ${ }^{11}$ In the past few years, the development of newer MDCT generation scanners has significantly lowered radiation exposure, which is gradually leading to increased adoption. ${ }^{12} 13$

However, the use of resource-consuming modalities requires evidence of additive impact on clinical management. It is still not clear if the quantitative advantages of these newer modalities have clinical

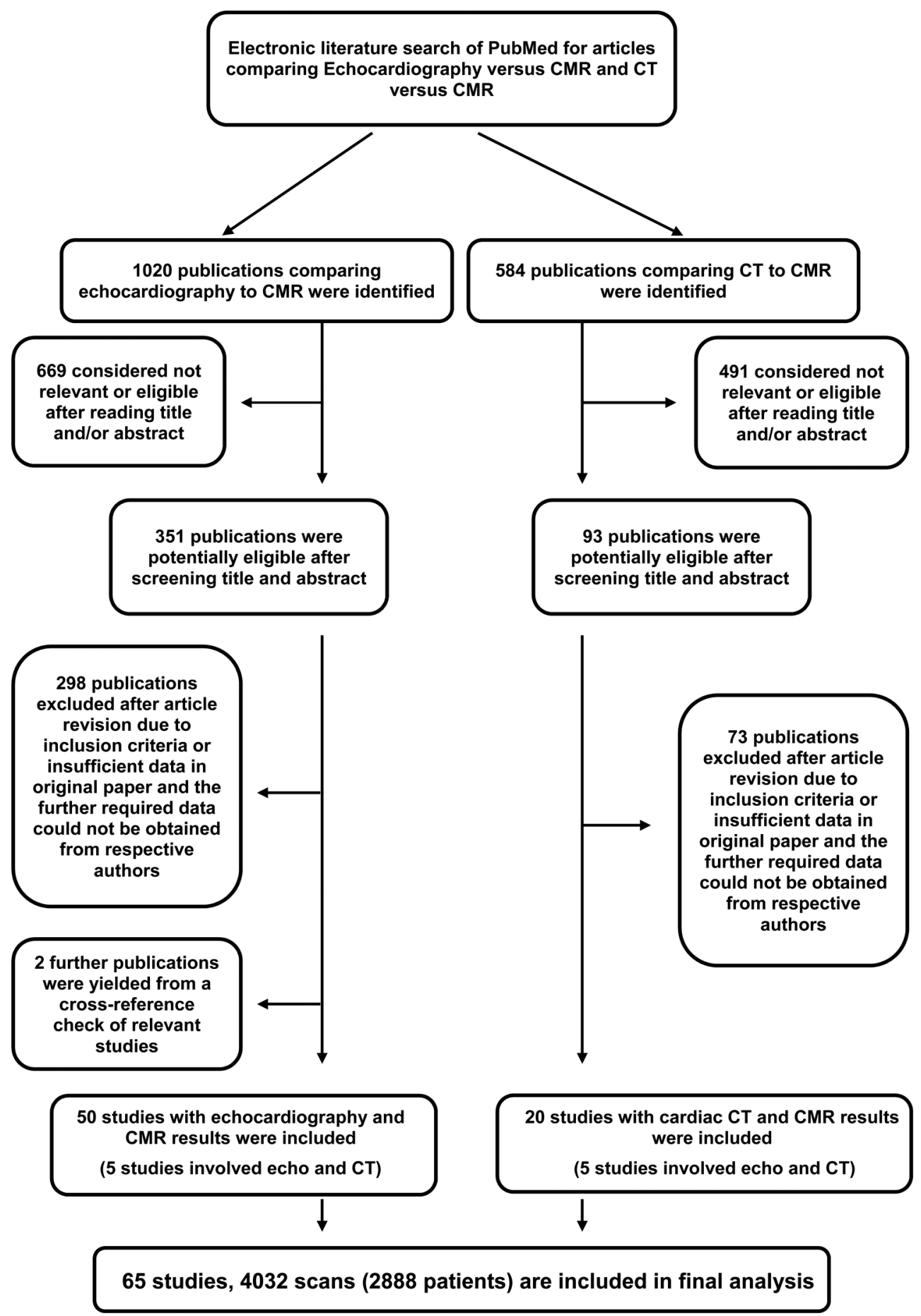

Figure 1 Study selection for inclusion. 
Table 1 Included studies

\begin{tabular}{|c|c|c|c|c|}
\hline First author* & $\begin{array}{l}\text { Publication } \\
\text { year }\end{array}$ & $\begin{array}{l}\text { Number of } \\
\text { patients }\end{array}$ & Population & $\begin{array}{l}\text { Modalities compared } \\
\text { to MRI }\end{array}$ \\
\hline Hundley & 1998 & 35 & Patients referred for evaluation of LV function & $\begin{array}{l}\text { 2D-echo (non-contrast), } \\
\text { 2D-echo (contrast) }\end{array}$ \\
\hline Schmidt & 1999 & 25 & 4 normal volunteers; 21 cardiac patients & 3D-echo (non-contrast) \\
\hline Chuang & 2000 & 35 & $\begin{array}{l}10 \text { healthy adult volunteers; } 25 \text { patients with dilated } \\
\text { cardiomyopathy }\end{array}$ & $\begin{array}{l}\text { 2D-echo (non-contrast), } \\
\text { 3D-echo (non-contrast) }\end{array}$ \\
\hline Qin & 2000 & 16 & Patients with normal LV & $\begin{array}{l}\text { 2D-echo (non-contrast), } \\
\text { 3D-echo (non-contrast) }\end{array}$ \\
\hline Chuang & 2001 & 24 & 12 obese/overweight patients and 12 lean patients & $\begin{array}{l}\text { 2D-echo (non-contrast), } \\
\text { 3D-echo (non-contrast) }\end{array}$ \\
\hline Schalla & 2001 & 34 & Cardiac patients & 2D-echo (non-contrast) \\
\hline Mannaerts & 2003 & 17 & $\begin{array}{l}7 \text { healthy volunteers and } 20 \text { patients with: hypertrophic } \\
\text { cardiomyopathy, aortic or mitral regurgitation, or AMI }\end{array}$ & 3D-echo (non-contrast) \\
\hline Zeidan & 2003 & 15 & Healthy volunteers & 3D-echo (non-contrast) \\
\hline Jenkins & 2004 & 50 & Patients referred to the echo laboratory & $\begin{array}{l}\text { 2D-echo (non-contrast), } \\
\text { 3D-echo (non-contrast) }\end{array}$ \\
\hline Malm & 2004 & 87 & Patients referred to the cardiology department & $\begin{array}{l}\text { 2D-echo (non-contrast), } \\
\text { 2D-echo (contrast) }\end{array}$ \\
\hline Caiani & 2005 & 46 & Patients with normal LV function & $\begin{array}{l}\text { 2D-echo (non-contrast), } \\
\text { 3D-echo (non-contrast) }\end{array}$ \\
\hline Corsi & 2005 & 16 & $\begin{array}{l}\text { Normal volunteers and patients with } \mathrm{CAD} \text {, dilated } \\
\text { cardiomyopathy, valvular disease }\end{array}$ & 3D-echo (non-contrast) \\
\hline Lim & 2005 & 36 & Stable patients with post-AMI & $\begin{array}{l}\text { 2D-echo (non-contrast), } \\
\text { 2D-echo (contrast) }\end{array}$ \\
\hline Wang & 2005 & 11 & Patients with chronic CAD & 2D-echo (non-contrast) \\
\hline Chan & 2006 & 30 & $\begin{array}{l}\text { Patients with previous AMI with altered shape and } \\
\text { wall-motion abnormalities }\end{array}$ & 3D-echo (non-contrast) \\
\hline Dewey & 2006 & 30 & Patients with suspected CAD & 2D-echo (non-contrast) \\
\hline Jenkins & 2006 & 110 & $\begin{array}{l}\text { Patients referred to the echo laboratory for } \\
\text { measurement of LV volumes and EF }\end{array}$ & $\begin{array}{l}\text { 2D-echo (non-contrast), } \\
\text { 3D-echo (non-contrast) }\end{array}$ \\
\hline Krenning & 2006 & 15 & $\begin{array}{l}\text { Male patients with a history of AMI and various degrees } \\
\text { of wall-motion abnormalities }\end{array}$ & 3D-echo (non-contrast) \\
\hline Liew & 2006 & 32 & Outpatient cardiac clinic patients with known CAD & $\begin{array}{l}\text { 2D-echo (non-contrast), } \\
\text { MDCT 64-slice }\end{array}$ \\
\hline Malm & 2006 & 50 & Patients submitted to echocardiography were enrolled & $\begin{array}{l}\text { 2D-echo (non-contrast), } \\
\text { 2D-echo (nontrast) }\end{array}$ \\
\hline Nigri & 2006 & 70 & $\begin{array}{l}35 \text { patients with aortic stenosis and } 35 \text { with aortic } \\
\text { regurgitation with surgical indication }\end{array}$ & 2D-echo (non-contrast) \\
\hline Nikitin & 2006 & 64 & $\begin{array}{l}40 \text { cardiac patients with LVEF }<45 \%, 14 \text { with EF }>45 \% \\
\text { and } 10 \text { normal volunteers }\end{array}$ & 3D-echo (non-contrast) \\
\hline Sugeng & 2006 & 31 & Patients referred for clinically indicated CT angiography & 3D-echo (non-contrast) \\
\hline Brodoefel & 2007 & 20 & Patients with chronic CAD & Dual source CT $2 \times 32$ \\
\hline Demir & 2007 & 21 & Patients with known or suspected CAD & 2D-echo (non-contrast) \\
\hline Giakoumis & 2007 & 135 & $\begin{array}{l}\text { Patients with thalassaemia major attending an } \\
\text { outpatient clinic }\end{array}$ & 2D-echo (non-contrast) \\
\hline Jenkins & 2007 & 50 & Patients with LV dysfunction due to previous AMI & $\begin{array}{l}\text { 2D-echo (non-contrast), } \\
\text { 3D-echo (non-contrast) }\end{array}$ \\
\hline Jenkins & 2007 & 30 & $\begin{array}{l}\text { Patients referred to the echo laboratory for } \\
\text { measurement of } L V \text { volumes and } E F\end{array}$ & $\begin{array}{l}\text { 2D-echo (non-contrast), } \\
\text { 3D-echo (non-contrast) }\end{array}$ \\
\hline Krenning & 2007 & 39 & $\begin{array}{l}\text { Patients referred for routine evaluation of cardiac } \\
\text { function after AMI }\end{array}$ & 3D-echo (non-contrast) \\
\hline Qi & 2007 & 58 & $\begin{array}{l}44 \text { patients with various cardiac disorders referred for } \\
\text { clinical MRI studies and } 14 \text { normal patients }\end{array}$ & 3D-echo (non-contrast) \\
\hline Schlosser & 2007 & 21 & Patients referred for CTCA & MDCT 64-slice \\
\hline Soliman & 2007 & 53 & $\begin{array}{l}\text { Patients with a cardiomyopathy and adequate } 2 \mathrm{D} \text { image } \\
\text { quality }\end{array}$ & 3D-echo (non-contrast) \\
\hline Bastarrika & 2008 & 12 & Patients heart transplant recipients & Dual source CT $32 \times 2$ \\
\hline Busch & 2008 & 15 & Mixed population of patients & Dual source CT $32 \times 2$ \\
\hline
\end{tabular}


Table 1 Continued

\begin{tabular}{|c|c|c|c|c|}
\hline First author* & $\begin{array}{l}\text { Publication } \\
\text { year }\end{array}$ & $\begin{array}{l}\text { Number of } \\
\text { patients }\end{array}$ & Population & $\begin{array}{l}\text { Modalities compared } \\
\text { to MRI }\end{array}$ \\
\hline Chukwu & 2008 & 69 & $\begin{array}{l}35 \text { with normal LV systolic function and } 34 \text { with } \mathrm{AMI} \text { and } \\
\text { depressed LV function }\end{array}$ & $\begin{array}{l}\text { 2D-echo (non-contrast), } \\
\text { 3D-echo (non-contrast) }\end{array}$ \\
\hline Leonardi & 2008 & 24 & Patients with thalassaemia & 2D-echo (non-contrast) \\
\hline Mor-Avi & 2008 & 92 & $\begin{array}{l}\text { Patients referred for CMR evaluation of LV size and } \\
\text { function }\end{array}$ & 3D-echo (non-contrast) \\
\hline Pouleur & 2008 & 83 & $\begin{array}{l}20 \text { volunteers and } 63 \text { patients with heart disease } \\
\text { including aortic valve disease, severe mitral } \\
\text { regurgitation and previous AMI }\end{array}$ & 3D-echo (non-contrast) \\
\hline Puesken & 2008 & 28 & Patients with known/suspected CAD & MDCT 64-slice \\
\hline Rutten & 2008 & 78 & $\begin{array}{l}\text { Mild to moderate patients with COPD with and without } \\
\text { heart failure }\end{array}$ & 2D-echo (non-contrast) \\
\hline Soliman & 2008 & 24 & $\begin{array}{l}17 \text { patients with impaired LV systolic function due to } \\
\text { CAD or idiopathic dilated cardiomyopathy }\end{array}$ & 3D-echo (non-contrast) \\
\hline $\mathrm{Wu}$ & 2008 & 41 & Mixed population of patients & MDCT 64-slice \\
\hline Akram & 2009 & 20 & Patients with suspected CAD & MDCT 64-slice \\
\hline Garcia-Alvarez & 2009 & 65 & $\begin{array}{l}\text { Patients with first STEMI admitted to a tertiary care } \\
\text { hospital and reperfused within } 12 \mathrm{~h} \text { of symptom onset }\end{array}$ & 2D-echo (non-contrast) \\
\hline Gardner & 2009 & 47 & $\begin{array}{l}\text { Patients with AMI greater than } 6 \text { weeks previously and } \\
\text { scheduled for imaging evaluation }\end{array}$ & 2D-echo (non-contrast) \\
\hline Gjesdal & 2009 & 61 & $\begin{array}{l}\text { Healthy controls and patients with acute STEMI and } \\
\text { treated with } \mathrm{PCl}\end{array}$ & 2D-echo (non-contrast) \\
\hline Guo & 2009 & 51 & $\begin{array}{l}\text { Patients with mitral regurgitation confirmed by 2D-echo } \\
\text { and colour Doppler }\end{array}$ & $\begin{array}{l}\text { 2D-echo (non-contrast), } \\
\text { MDCT 64-slice }\end{array}$ \\
\hline Jenkins & 2009 & 50 & $\begin{array}{l}\text { Patients with past AMI who underwent } \\
\text { echocardiographic assessment of LV volume and } \\
\text { function }\end{array}$ & $\begin{array}{l}\text { 2D-echo (non-contrast), } \\
\text { 2D-echo (contrast), } \\
\text { 3D-echo (non-contrast) }\end{array}$ \\
\hline Nowosielski & 2009 & 52 & Patients with first $\mathrm{AMI}$ and $\mathrm{PCl}$ & 2D-echo (non-contrast) \\
\hline Sarwar & 2009 & 21 & Patients with STEMI & MDCT 64-slice \\
\hline Abbate & 2010 & 10 & Patients with ST-segment elevation AMI & 2D-echo (non-contrast) \\
\hline Claver & 2010 & 43 & $\begin{array}{l}\text { Unselected patients who underwent CMR; mixed } \\
\text { cardiac pathologies }\end{array}$ & 3D-echo (non-contrast) \\
\hline Palumbo & 2010 & 181 & Patients with suspected CAD, indexed volumes & MDCT 64-slice \\
\hline Whalley & 2010 & 25 & Patients with at least moderate MR due to MV prolapse & 2D-echo (non-contrast) \\
\hline De Jonge & 2011 & 26 & Patients referred for CTCA & Dual source CT $2 \times 32$ \\
\hline Arraiza & 2012 & 25 & Patients heart transplant recipients & $\begin{array}{l}\text { 2D-echo (contrast), dual } \\
\text { source CT } 2 \times 32\end{array}$ \\
\hline Bak & 2012 & 111 & Patients referred for CTCA before valve surgery & $\begin{array}{l}\text { 2D-echo (non-contrast), } \\
\text { dual source } 2 \times 32\end{array}$ \\
\hline Brodoefel & 2012 & 20 & Patients with known or suspected CAD & Dual source CT $2 \times 32$ \\
\hline Coon & 2012 & 18 & $\begin{array}{l}\text { Patients with CAD, dilated cardiomyopathy, post-AMI, } \\
\text { aortic abnormalities and mitral valve disease }\end{array}$ & $\begin{array}{l}\text { 3D-echo (non-contrast), } \\
\text { 3D-echo (contrast) }\end{array}$ \\
\hline Fuchs & 2012 & 53 & Patients with previous AMI & MDCT 64-slice \\
\hline Greupner & 2012 & 36 & Patients referred for CTCA & $\begin{array}{l}\text { 2D-echo (non-contrast), } \\
\text { 3D-echo (non-contrast), } \\
\text { MDCT 64-slice }\end{array}$ \\
\hline Lee & 2012 & 30 & $\begin{array}{l}\text { Patients who had undergone clinically indicated, routine } \\
\text { CCTA studies }\end{array}$ & MDCT 64-slice \\
\hline $\mathrm{Li}$ & 2012 & 72 & Mixed population of cardiac patients & 2D-echo (non-contrast) \\
\hline Maffei & 2012 & 79 & Patients referred for CTCA, indexed volumes & MDCT 64-slice \\
\hline Takx & 2012 & 20 & Patients with known or suspected CAD & Dual source CT $2 \times 32$ \\
\hline Total & $1998-2013$ & 2888 & $\begin{array}{l}\text { 2D Echo (NC): } 32 \text { studies/1663 examinations } \\
\text { 2D Echo (C): } 6 \text { studies/283 examinations } \\
\text { 3D Echo (NC): } 27 \text { studies/1137 examinations } \\
\text { 3D Echo (C): } 3 \text { studies/107 examinations } \\
\text { MDCT: } 20 \text { studies/842 examinations }\end{array}$ & $\begin{array}{l}50 \text { Echo and } 20 \mathrm{CT}(5 \\
\text { of these included echo } \\
\text { and CT) }\end{array}$ \\
\hline
\end{tabular}

2D, two-dimensional echo; AMI, acute myocardial infarction; C, contrast; CAD, coronary artery disease; CMR, cardiac MR; COPD, chronic obstructive pulmonary disease; CTCA, CT coronary angiography; EF, ejection fraction; LV, left ventricular; LVEF, left ventricular ejection fraction; MDCT, multidetector CT; MV, mitral valve; NC, non-contrast; PCI, percutaneous coronary intervention; STEMI, ST segment elevation myocardial infarction.

*See online supplementary file for citations. 
Table 2 Summary of meta-regression of differences observed by each method

\begin{tabular}{|c|c|c|c|c|c|c|c|c|c|c|}
\hline \multirow[b]{2}{*}{ Imaging modality } & \multirow[b]{2}{*}{$\begin{array}{l}\text { Year } \\
\text { published }\end{array}$} & \multicolumn{9}{|c|}{ Mean difference compared to cardiac MR } \\
\hline & & $\begin{array}{l}\text { LVEDV (mL) } \\
(95 \% \mathrm{Cl})\end{array}$ & $\begin{array}{l}\text { Overall } \\
\text { p value }\end{array}$ & $\begin{array}{l}\mathrm{I}^{2} \\
\mathrm{p} \text { value }\end{array}$ & $\begin{array}{l}\text { LVESV (mL) } \\
(95 \% \mathrm{Cl})\end{array}$ & $\begin{array}{l}\text { Overall } \\
\text { p value }\end{array}$ & $\begin{array}{l}\mathrm{I}^{2} \\
\mathrm{p} \text { value }\end{array}$ & $\begin{array}{l}\text { LVEF (\%) } \\
(95 \% \mathrm{CI})\end{array}$ & $\begin{array}{l}\text { Overall } \\
\text { p value }\end{array}$ & $\begin{array}{l}I^{2} \\
p \text { value }\end{array}$ \\
\hline \multirow{4}{*}{$\begin{array}{l}\text { 2D-echocardiography } \\
\text { Volumes } \mathrm{N}=1579, \\
\text { LVEF } \mathrm{N}=1683\end{array}$} & Overall & $\begin{array}{l}-33.26 \\
(-43.42 \text { to }-20.65)\end{array}$ & $<0.0001$ & $\begin{array}{l}87 \% \\
p<0.0001\end{array}$ & $\begin{array}{l}-16.20 \\
(-21.36 \text { to }-11.04)\end{array}$ & $<0.0001$ & $\begin{array}{l}73 \% \\
<0.0001\end{array}$ & $\begin{array}{l}-0.66 \\
(-2.14 \text { to } 0.82)\end{array}$ & 0.38 & $\begin{array}{l}72 \% \\
<0.0001\end{array}$ \\
\hline & $<2005$ & $\begin{array}{l}-23.23 \\
(-43.86 \text { to }-2.59)\end{array}$ & 0.03 & $\begin{array}{l}77 \% \\
p<0.0001\end{array}$ & $\begin{array}{l}-12.15 \\
(-18.55 \text { to }--5.75)\end{array}$ & 0.0002 & $0 \% 0.05$ & $\begin{array}{l}-2.11 \\
(-4.48 \text { to } 0.26)\end{array}$ & 0.08 & $3 \% 0.40$ \\
\hline & 2005-2009 & $\begin{array}{l}-33.49 \\
(-46.88 \text { to }-20.09)\end{array}$ & $<0.0001$ & $\begin{array}{l}90 \% \\
p<0.0001\end{array}$ & $\begin{array}{l}-17.73 \\
(-25.11 \text { to }-10.36)\end{array}$ & $<0.0001$ & $\begin{array}{l}81 \% \\
<0.0001\end{array}$ & $\begin{array}{l}-0.26 \\
(-2.32 \text { to } 1.81)\end{array}$ & 0.81 & $\begin{array}{l}81 \% \\
<0.0001\end{array}$ \\
\hline & $>2009$ & $\begin{array}{l}-46.46 \\
(-72.27 \text { to }-20.65)\end{array}$ & 0.0004 & $\begin{array}{l}83 \% \\
p<0.0001\end{array}$ & $\begin{array}{l}-18.73 \\
(-29.46 \text { to }-8.01)\end{array}$ & 0.0006 & $58 \% 0.05$ & $\begin{array}{l}-1.14 \\
(-3.03 \text { to } 0.21)\end{array}$ & 0.09 & $0 \% 0.67$ \\
\hline $\begin{array}{l}\text { 2D-echocardiography } \\
\text { with contrast } \\
\text { Volumes and LVEF } \\
\mathrm{N}=283\end{array}$ & Overall* $^{*}$ & $\begin{array}{l}-18.05 \\
(-6.39 \text { to }-9.7)\end{array}$ & $<0.0001$ & $0 \% p=0.45$ & $\begin{array}{l}-7.84 \\
(-14.46 \text { to }-1.22)\end{array}$ & 0.02 & $0 \% p=0.99$ & $\begin{array}{l}-1.03 \\
(-3.38 \text { to } 1.35)\end{array}$ & 0.39 & $0 \% p=0.61$ \\
\hline \multirow{4}{*}{$\begin{array}{l}\text { 3D-echocardiography } \\
\text { Volumes } \mathrm{N}=1159 \text {, } \\
\text { LVEF } \mathrm{N}=1104\end{array}$} & Overall & $\begin{array}{l}-14.16 \\
(-18.66 \text { to }-9.66)\end{array}$ & $<0.0001$ & $23 \% p=0.12$ & $\begin{array}{l}-6.49 \\
(-9.91 \text { to }-3.07)\end{array}$ & 0.0002 & $0 \% p=0.96$ & $\begin{array}{l}0.13 \\
(-0.91 \text { to } 1.16)\end{array}$ & 0.81 & $0 \% p=1.00$ \\
\hline & $<2005$ & $\begin{array}{l}-15.14 \\
(-25.17 \text { to }-5.12)\end{array}$ & 0.003 & $0 \% p=0.49$ & $\begin{array}{l}-6.38 \\
(-13.36 \text { to } 0.60)\end{array}$ & 0.07 & $0 \% p=0.91$ & $\begin{array}{l}0.25 \\
(-2.09 \text { to } 2.59)\end{array}$ & 0.83 & $0 \% p=1.00$ \\
\hline & 2005-2009 & $\begin{array}{l}-13.32 \\
(-18.64 \text { to }-8.01)\end{array}$ & $<0.0001$ & $43 \% p=0.01$ & $\begin{array}{l}-6.27 \\
(-10.41 \text { to }-2.13)\end{array}$ & 0.003 & $0 \% p=0.72$ & $\begin{array}{l}0.02 \\
(-1.20 \text { to } 1.23)\end{array}$ & 0.98 & $0 \% p=0.99$ \\
\hline & $>2009$ & $\begin{array}{l}-18.95 \\
(-34.54 \text { to }-3.36)\end{array}$ & 0.02 & $0 \% p=0.86$ & $\begin{array}{l}-8.77 \\
(-21.00 \text { to } 3.47)\end{array}$ & 0.16 & $0 \% p=0.84$ & $\begin{array}{l}0.89 \\
(-2.93 \text { to } 4.70)\end{array}$ & 0.65 & $9 \% p=0.33$ \\
\hline \multirow{3}{*}{$\begin{array}{l}\text { Multidetector CT } \\
\text { Volumes } \mathrm{N}=790 \text {, } \\
\text { LVEF } \mathrm{N}=780\end{array}$} & Overall & $\begin{array}{l}-1.16 \\
(-4.14 \text { to } 1.83)\end{array}$ & 0.45 & $0 \% p=0.90$ & $\begin{array}{l}-0.11 \\
(-2.40 \text { to } 2.18)\end{array}$ & 0.93 & $0 \% p=0.96$ & $\begin{array}{l}0.86 \\
(-0.21 \text { to } 1.94)\end{array}$ & 0.12 & $0 \% p=0.55$ \\
\hline & 2007-2009 & $\begin{array}{l}5.21 \\
(-2.13 \text { to } 12.54)\end{array}$ & 0.16 & $0 \% p=0.74$ & $\begin{array}{l}2.59 \\
(-1.19 \text { to } 6.36)\end{array}$ & 0.18 & $0 \% p=0.93$ & $\begin{array}{l}0.45 \\
(-1.27 \text { to } 2.17)\end{array}$ & 0.51 & $0 \% p=0.94$ \\
\hline & $>2009$ & $\begin{array}{l}-2.41 \\
(-5.68 \text { to } 0.85)\end{array}$ & 0.15 & $0 \% p=0.99$ & $\begin{array}{l}-1.68 \\
(-4.56 \text { to } 1.21)\end{array}$ & 0.25 & $0 \% p=0.97$ & $\begin{array}{l}1.13 \\
(-0.25 \text { to } 2.50)\end{array}$ & 0.11 & $4 \% p=0.40$ \\
\hline
\end{tabular}

Values are mean $(95 \% \mathrm{Cl})$

*Insufficient number of studies for subgroup analysis.

LVEDV, Left ventricular end-diastolic volume; LVEF, left ventricular ejection fraction; LVESV, left ventricular end-systolic volume. 


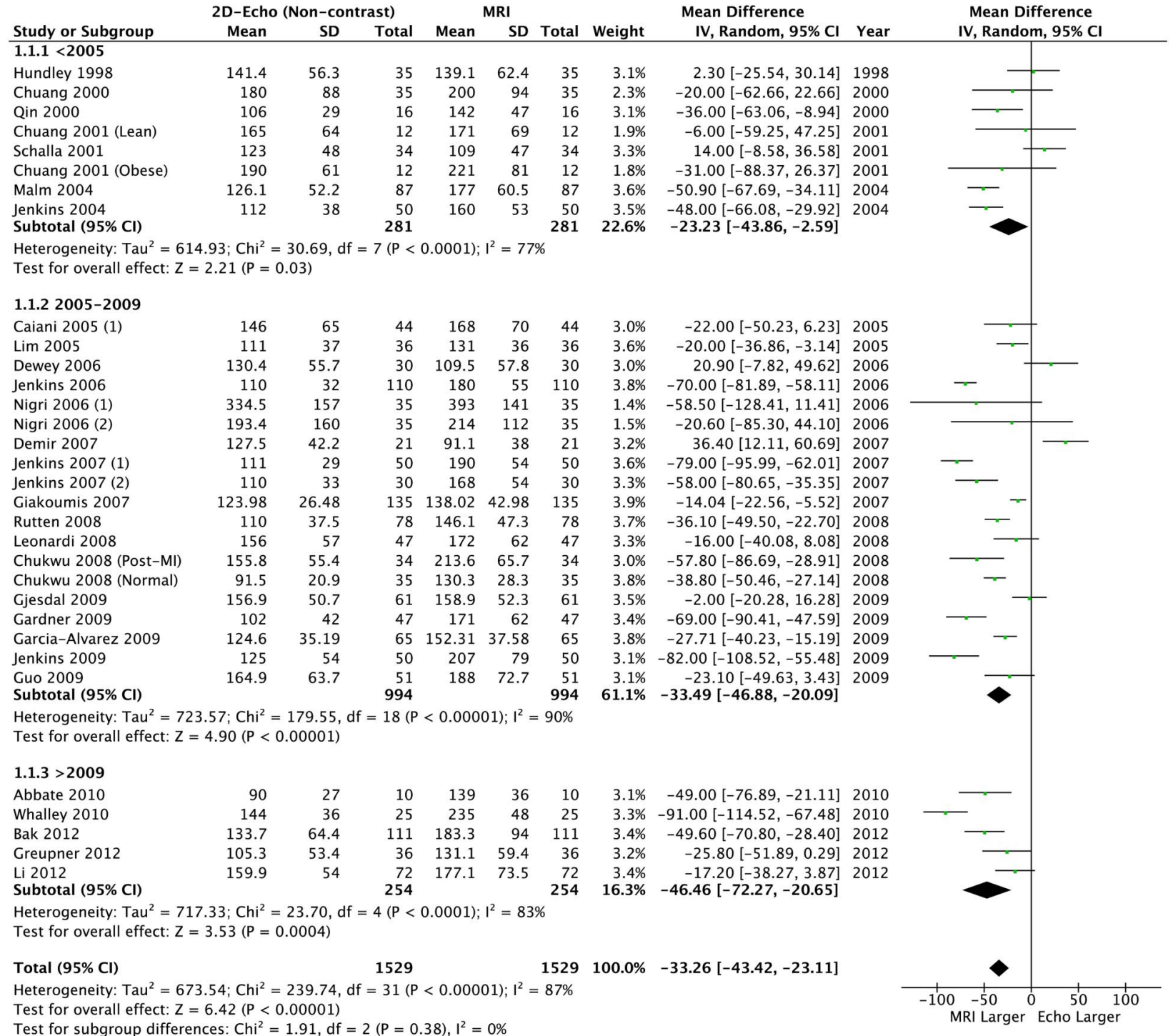

Figure 2 Left ventricular end-diastolic volume: 2D echo versus CMR. CMR, cardiac MR; 2D, two-dimensional.

significance. The physician should be aware of the difference between modalities when applying the common cut-off for evaluation and follow-up of patients who frequently undergo different types of tests. Moreover, the advances in multi-imaging may have recently been granted higher accuracy due to technical improvements and greater experience. These are the reasons why we sought to assess the difference in absolute values of bias in volumetric and functional LV quantification that may help clinical evaluation. Thus, the aim of our systematic review was to investigate the accuracy of LV assessment by different noninvasive imaging modalities, with a focus on the measurements adopted for patient management.

\section{MATERIALS AND METHODS}

The meta-analysis conforms to the Meta-analysis Of Observational Studies in Epidemiology (MOOSE) guidelines.

\section{Search strategy}

The authors developed these strategies for database searching: the MEDLINE/PubMed database was searched from January 1995 in consideration of the fact that the steady state free precession (SSFP) MRI technique that is currently used for CMR cine images acquisition was only available in the late 1990s. The literature search was limited to human adults in order to exclude studies involving children with congenital heart disease and consequent abnormal cardiac geometry. Abstracts and articles published in languages other than English were not excluded. A total of 1604 articles published over a period of 19 years were identified for initial review: 1020 and 584 in the echocardiography and CT groups, respectively.

\section{Echocardiographic modalities versus CMR search}

The search strategy was determined (by GW and JC) and the first initial literature search carried out (by SA), and an updated version (by MR) was then performed, 


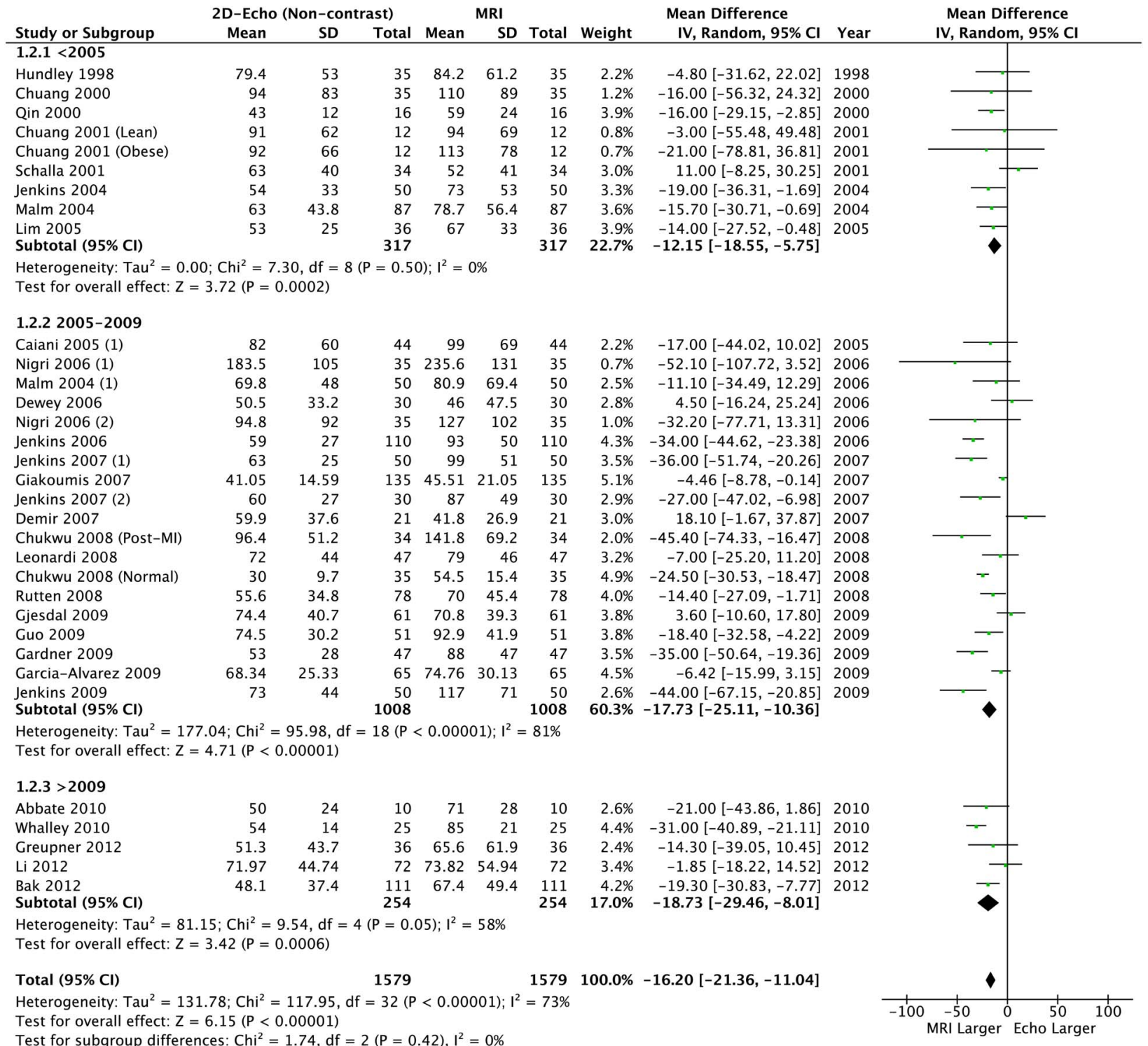

using the following search terms: heart OR heart ventricles OR ventric*.mp AND left.mp AND cardiac volume OR heart volume OR cardiac output OR ventricular function OR ventricular dysfunction AND echocardiography OR echo.mp OR echocardiogram*.mp AND MRI OR magnetic resonance spectroscopy OR MRI.mp OR MR scan.mp OR magnetic resonance scan*.mp. The titles and abstracts of all studies identified were initially screened (by SA and MR) and reviewed (by MR and GW).

\section{CT versus CMR search}

The initial search for volumetric comparison between CT and CMR was conducted using the following search terms: heart OR cardiac OR ventricular OR ventricle OR cardiovascular AND volume OR volumes OR volumetric OR function OR dysfunction OR cardiac output AND magnetic resonance OR MRI OR MR OR MRI AND CT OR CT OR dual-source OR multi-detector OR
MDCT. The titles and abstracts of all studies identified were initially screened (by SA) and reviewed (by MR and GW).

\section{All modalities}

A cross-reference process was undertaken (by SA) to search and the studies initially identified in the separate searches and the final papers were reviewed by the other authors (MR and GW). The reference lists were manually searched for potential other studies, and duplicate studies were identified and excluded.

\section{Criteria for study selection}

We excluded individual case reports, studies involving a sample size of $<10$ patients and those that included patients with unusual geometry (eg, congenital heart disease, Takotsubo and hypertrophic cardiomyopathy). Only newer generation CT scanners were included: at 


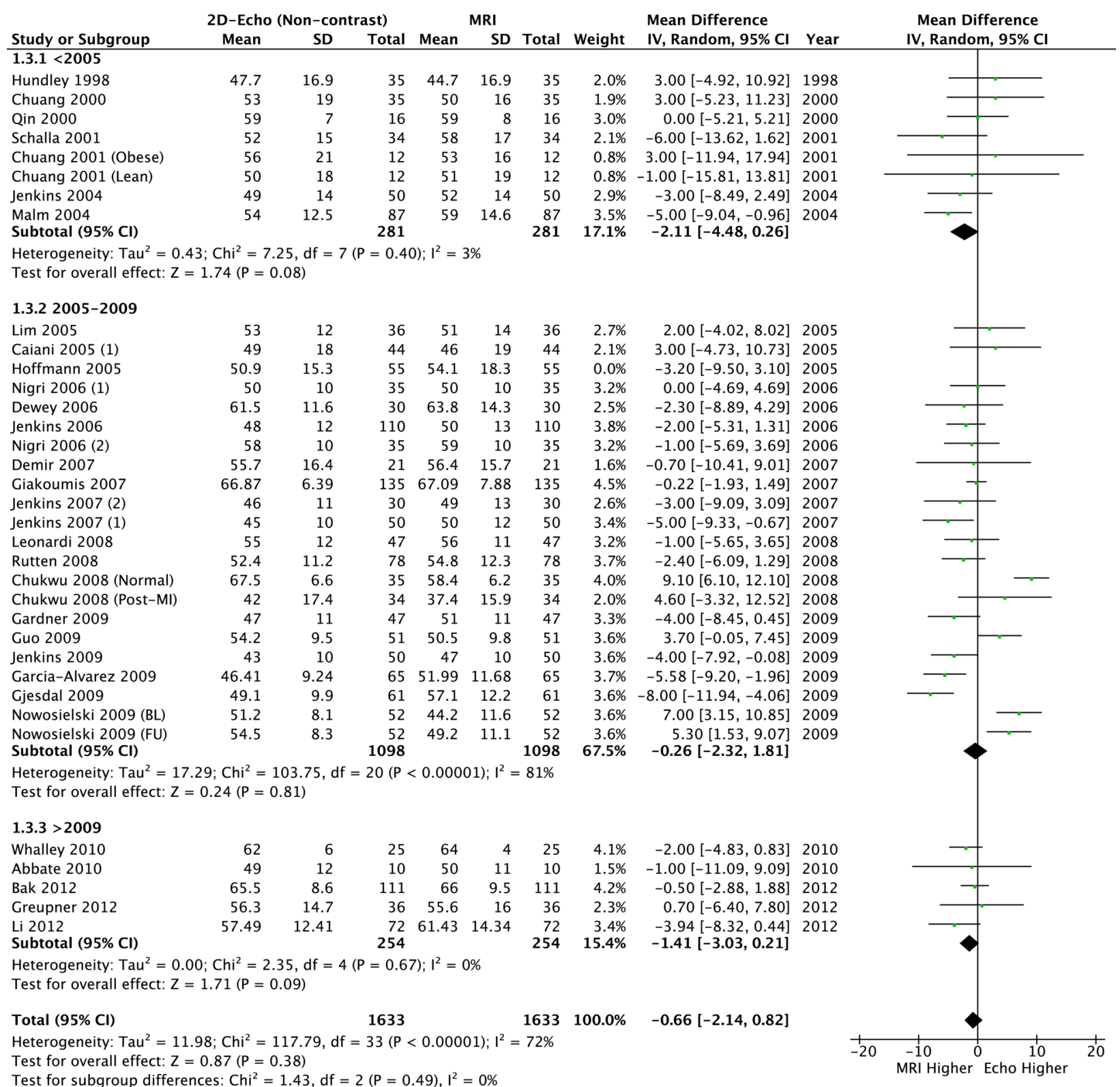

Figure 4 Left ventricular ejection fraction: 2D echo versus CMR. CMR, cardiac MR; 2D, two-dimensional

least MDCT 64 slice or dual source CT (DSCT) $2 \times 32$ slice for their improved temporal resolution and Z-axis coverage. Following these exclusions, 351 echocardiography and 93 MDCT articles were available for full review.

\section{Data extraction}

Data were extracted and recorded in an electronic database including: number of patients who received echocardiography, CT and MRI; and group mean values and SDs for LV end-diastolic volume (LVEDV), LV end-

\begin{tabular}{|c|c|c|c|c|c|c|c|c|c|c|c|}
\hline \multirow[b]{2}{*}{ Study or Subgroup } & \multicolumn{3}{|c|}{ 2D-Echo (Contrast) } & \multicolumn{3}{|c|}{ MRI } & \multicolumn{3}{|c|}{ Mean Difference } & \multirow{2}{*}{\multicolumn{2}{|c|}{$\begin{array}{l}\text { Mean Difference } \\
\text { IV, Fixed, } 95 \% \mathrm{CI}\end{array}$}} \\
\hline & Mean & SD & Total & Mean & SD & Total & Weight & IV, Fixed, 95\% CI & Year & & \\
\hline Hundley 1998 & 134 & 60.9 & 35 & 139.1 & 62.4 & 35 & $8.4 \%$ & $-5.10[-33.99,23.79]$ & 1998 & & \\
\hline Malm 2004 & 152.2 & 55.1 & 87 & 177 & 60.5 & 87 & $23.6 \%$ & $-24.80[-42.00,-7.60]$ & 2004 & - - & \\
\hline Lim 2005 & 121 & 41 & 36 & 131 & 36 & 36 & $21.9 \%$ & $-10.00[-27.82,7.82]$ & 2005 & $\longrightarrow-$ & \\
\hline Jenkins 2009 & 172 & 58 & 50 & 207 & 79 & 50 & $9.4 \%$ & $-35.00[-62.17,-7.83]$ & 2009 & & \\
\hline Arraiza 2012 & 86.7 & 24.2 & 25 & 103.8 & 25.5 & 25 & $36.7 \%$ & $-17.10[-30.88,-3.32]$ & 2012 & -- & \\
\hline Total $(95 \% \mathrm{Cl})$ & & & 233 & & & 233 & $100.0 \%$ & $-18.05[-26.39,-9.70]$ & & & \\
\hline $\begin{array}{l}\text { Heterogeneity: } \mathrm{Chi}^{2} \\
\text { Test for overall effec }\end{array}$ & $\begin{array}{l}66, \mathrm{df} \\
=4.24\end{array}$ & $(P=$ & $.45) ; 1^{2}$ & $0 \%$ & & & & & & $\begin{array}{ccc}-100 & -50 & 0 \\
& \text { MRI Larger }\end{array}$ & \begin{tabular}{|lcc}
0 & 50 & 100 \\
Echo Larger
\end{tabular} \\
\hline
\end{tabular}

Figure 5 Left ventricular end-diastolic volume: 2D echo with contrast versus CMR. CMR, cardiac MR; 2D, two-dimensional. 


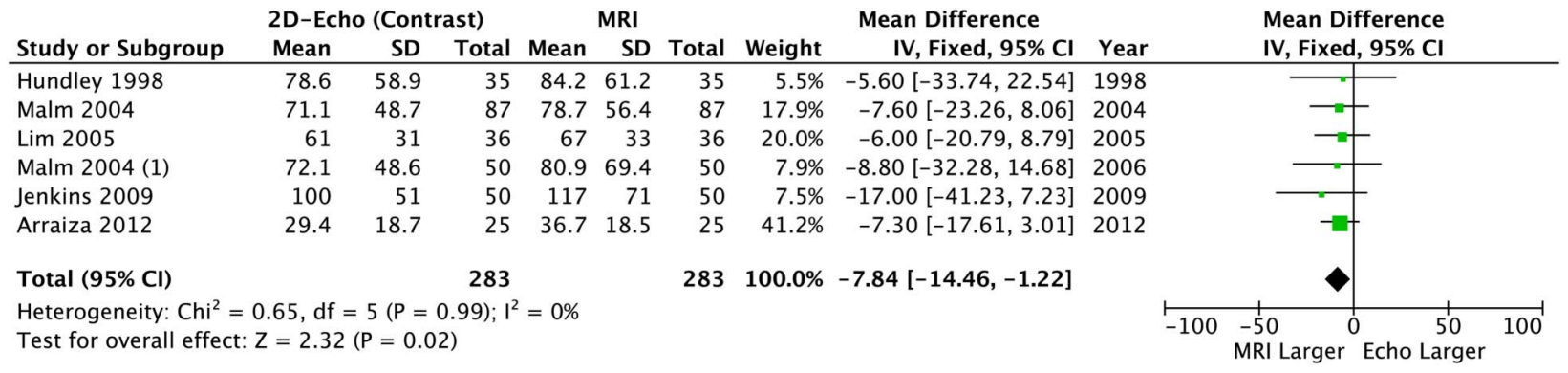

Figure 6 Left ventricular end-systolic volume: 2D echo with contrast versus CMR. CMR, cardiac MR; 2D, two-dimensional.

systolic volume (LVESV) and LVEF. Where the article content was insufficient, the corresponding or senior authors of the studies were contacted for further information. In the case of potential duplicate publications, clarification was sought from the authors and the largest single published data set was used for the systematic review. At the same time, additional references to either published or unpublished studies were sought.

\section{Statistical analysis}

Analyses of the collected data were performed using the Cochrane Collaboration Program Review Manager V.5.2 software. Data were collected from individual studies and weighted according to number of patients in the sample. Mean LVEDV, LVESV, LVEF and correspondent SD were used to calculate a pool estimate of the three parameters. The $\chi^{2}$ test was adopted to determine heterogeneity. Study variation due to heterogeneity was evaluated with inconsistency $\left(\mathrm{I}^{2}\right)$. $\mathrm{I}^{2}$ values $>30 \%$ were considered as significant variation. Funnel plots were used to evaluate study-level and publication bias. Absolute pooled mean values and CIs (95\%) were tested with the fixed effect model of Mantel-Hanszel in case of homogeneity, and with the random effect model of DerSimonian-Laird if heterogeneity was reported. A p value $<0.05$ was considered significant.

\section{RESULTS}

We identified 1020 echocardiography and 584 CT publications. Of these, 351 and 93 were considered potentially eligible. Two additional studies were found from a cross-reference check of relevant studies. After screening the full-text articles for relevance and eligibility, 50 articles comparing echocardiography to MRI and 20 studies comparing CT to MRI remained (figure 1). Owing to the overlap of five studies that analysed both echocardiography and CT versus MRI, the total number of studies included was 65 (table 1, reference list is available as online supplementary data). All the articles or abstracts were published in peer-review journals.

\section{D Echocardiography and CMR comparison}

Overall, 2888 patients (4032 scans) were included. Compared to CMR, there were significant differences in LVEDV and LVESV, with observed high levels of heterogeneity $(87 \%)$ and bias from funnel plots (table 2, figures 2 and 3). Although a significant bias was not detected for LVEF (mean difference: $-0.78 \%$ (95\% CI $-2.24 \%$ to -0.68$)$ ), similar high levels of heterogeneity (72\%) and bias were observed (table 2 and figure 4). This heterogeneity renders the calculated mean difference unreliable, but it does highlight a clinically relevant underestimation of the volumes and supports the overall findings that these methods are not interchangeable.

\section{D echocardiography with contrast and CMR comparison}

When contrast was added to 2DE, significant differences in LVEDV and LVESV remained: CE-2DE underestimated both volume measurements (table 2, figures 5 and 6) but LVEF was similar compared to CMR and neither heterogeneity nor bias was seen (table 2 and figure 7).

\begin{tabular}{|c|c|c|c|c|c|c|c|c|c|c|c|c|}
\hline \multirow[b]{2}{*}{ Study or Subgroup } & \multicolumn{3}{|c|}{ 2D-Echo (Contrast) } & \multicolumn{3}{|c|}{ MRI } & \multicolumn{3}{|c|}{ Mean Difference } & \multirow{2}{*}{\multicolumn{3}{|c|}{$\begin{array}{l}\text { Mean Difference } \\
\text { IV, Fixed, } 95 \% \mathrm{Cl}\end{array}$}} \\
\hline & Mean & SD & Total & Mean & SD & Total & Weight & IV, Fixed, 95\% CI & Year & & & \\
\hline Hundley 1998 & 46.3 & 16.8 & 35 & 44.7 & 16.9 & 35 & $8.9 \%$ & $1.60[-6.29,9.49]$ & 1998 & & & \\
\hline Malm 2004 & 57 & 13.3 & 87 & 59 & 14.6 & 87 & $32.2 \%$ & $-2.00[-6.15,2.15]$ & 2004 & & & \\
\hline $\operatorname{Lim} 2005$ & 51 & 14 & 36 & 51 & 14 & 36 & $13.2 \%$ & $0.00[-6.47,6.47]$ & 2005 & & & \\
\hline Jenkins 2009 & 44 & 12 & 50 & 47 & 10 & 50 & $29.5 \%$ & $-3.00[-7.33,1.33]$ & 2009 & & & \\
\hline Arraiza 2012 & 67.3 & 10.4 & 25 & 65.1 & 10.7 & 25 & $16.2 \%$ & $2.20[-3.65,8.05]$ & 2012 & & - & \\
\hline Total $(95 \% \mathrm{Cl})$ & & & 233 & & & 233 & $100.0 \%$ & $-1.03[-3.38,1.32]$ & & & & \\
\hline $\begin{array}{l}\text { Heterogeneity: } \mathrm{Chi}^{2}= \\
\text { Test for overall effect }\end{array}$ & $\begin{array}{l}2.70, \mathrm{df} \\
Z=0.86\end{array}$ & $\begin{array}{l}4(P= \\
=0.3\end{array}$ & $61) ; 1^{2}$ & $=0 \%$ & & & & & & $\longmapsto_{-100}$ & $\begin{array}{ccc}1 & 1 & 1 \\
-50 & 0 & 50 \\
\text { MRI Larger } & \text { Echo Larger }\end{array}$ & 100 \\
\hline
\end{tabular}

Figure 7 Left ventricular ejection fraction: 2D echo with contrast versus CMR. CMR, cardiac MR; 2D, two-dimensional. 


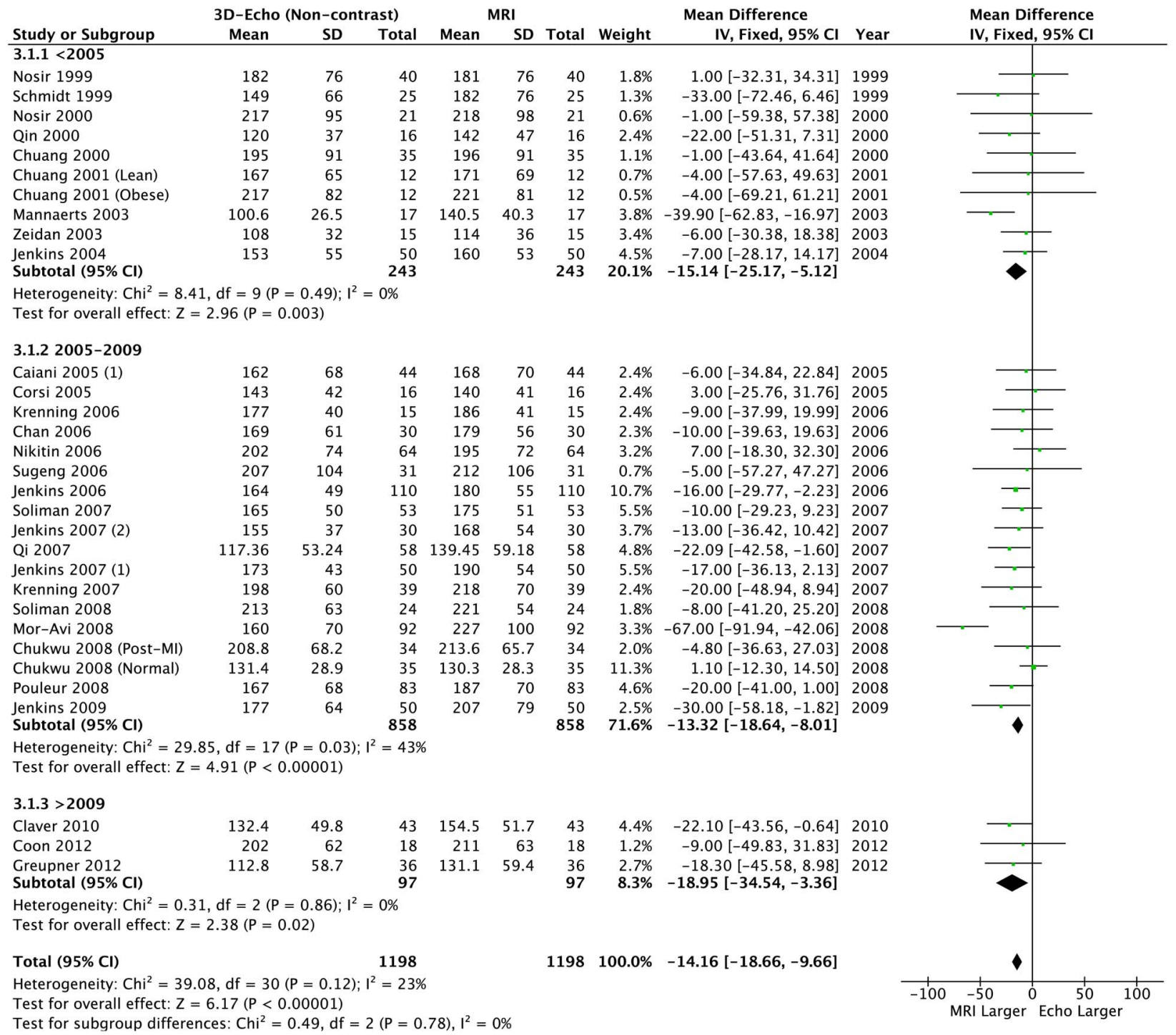

Figure 8 Left ventricular end-diastolic volume: 3D echo versus CMR. CMR, cardiac MR; 3D, three-dimensional.

\section{D echocardiography and CMR comparison}

Using 3DE further reduced the absolute size of the bias, but significant underestimation remained for LVEDV and LVESV (table 2, figures 8 and 9). However LVEF was similar and neither heterogeneity nor bias was seen (table 2 and figure 10).

\section{CT and CMR comparison}

Of the $20 \mathrm{CT}$ studies that were included, 12 adopted a 64-slice MDCT, while the remaining eight employed a dual source technology $(2 \times 32$ slices $)$. No differences were observed between CT and CMR for any volume or LVEF measure, and heterogeneity was uniformly absent; also, the funnel plots revealed no bias (table 2 and figures 11-13).

When considered over time, no significant differences in the summary statistics were seen for any measure or modality with widely overlapping CIs, suggesting no obvious impact of improved technology over this time period.

\section{DISCUSSION}

To the best of our knowledge, this is the first meta-analysis to evaluate all of the most commonly available non-invasive modalities for LV volume and LVEF quantification over nearly two decades of literature search. Our data show that 3DE provides the highest accuracy for LVEF quantification, while newer generation CT is the most precise method for assessment of LV volumes, when compared to CMR. Moreover, 2DE (non-contrast and contrast-enhanced) significantly underestimates $\mathrm{LV}$ volumes.

Despite the clinical importance of $\mathrm{LV}$ volumetric and functional quantification, no consensus remains on the best modality for assessment. Although it is acknowledged that bias may occur, the absolute differences in LV volumes and LVEF by various imaging methods are largely unquantifiable. It is important to determine, and quantify, if there is a significant absolute bias between modalities especially for follow-up that nowadays is increasingly performed with different types of 


\begin{tabular}{|c|c|c|c|c|c|c|c|c|c|c|c|}
\hline \multirow{3}{*}{$\begin{array}{l}\text { Study or Subgroup } \\
3.2 .1<2005\end{array}$} & \multicolumn{3}{|c|}{ 3D-Echo (Non-contrast) } & \multicolumn{3}{|c|}{ MRI } & \multicolumn{3}{|c|}{ Mean Difference } & \multirow{2}{*}{\multicolumn{2}{|c|}{$\begin{array}{l}\text { Mean Difference } \\
\text { IV, Fixed, 95\% CI }\end{array}$}} \\
\hline & Mean & SD & Total & Mean & SD & Total & Weight & IV, Fixed, 95\% Cl & Year & & \\
\hline & & & & & & & & & & & \\
\hline Nosir 1999 & 122 & 77 & 40 & 120 & 76 & 40 & $1.0 \%$ & $2.00[-31.53,35.53]$ & 1999 & & \\
\hline Schmidt 1999 & 70 & 35 & 25 & 70 & 43 & 25 & $2.5 \%$ & $0.00[-21.73,21.73]$ & 1999 & & - \\
\hline Qin 2000 & 50 & 17 & 16 & 59 & 24 & 16 & $5.6 \%$ & $-9.00[-23.41,5.41]$ & 2000 & & \\
\hline Chuang 2000 & 104 & 90 & 35 & 105 & 91 & 35 & $0.6 \%$ & $-1.00[-43.40,41.40]$ & 2000 & & \\
\hline Nosir 2000 & 155 & 99 & 21 & 154 & 98 & 21 & $0.3 \%$ & $1.00[-58.58,60.58]$ & 2000 & & \\
\hline Chuang 2001 (Obese) & 112 & 80 & 12 & 113 & 78 & 12 & $0.3 \%$ & $-1.00[-64.22,62.22]$ & 2001 & & \\
\hline Chuang 2001 (Lean) & 93 & 65 & 12 & 94 & 69 & 12 & $0.4 \%$ & $-1.00[-54.63,52.63]$ & 2001 & & \\
\hline Zeidan 2003 & 43 & 18 & 15 & 47 & 21 & 15 & $6.0 \%$ & $-4.00[-18.00,10.00]$ & 2003 & & t \\
\hline Mannaerts 2003 & 40.8 & 20.7 & 17 & 60.6 & 28.5 & 17 & $4.2 \%$ & $-19.80[-36.54,-3.06]$ & 2003 & . & \\
\hline $\begin{array}{l}\text { Jenkins } 2004 \\
\text { Subtotal }(95 \% \mathrm{CI})\end{array}$ & 74 & 47 & $\begin{array}{r}50 \\
243\end{array}$ & 73 & 53 & $\begin{array}{r}50 \\
243\end{array}$ & $\begin{array}{r}3.0 \% \\
24.0 \%\end{array}$ & $\begin{array}{c}1.00[-18.63,20.63] \\
-6.38[-13.36,0.60]\end{array}$ & 2004 & & - \\
\hline \multicolumn{12}{|c|}{$\begin{array}{l}\text { Heterogeneity: } \mathrm{Chi}^{2}=4.01, \mathrm{df}=9(P=0.91) ; I^{2}=0 \% \\
\text { Test for overall effect: } Z=1.79(P=0.07)\end{array}$} \\
\hline \multicolumn{12}{|l|}{$3.2 .22005-2009$} \\
\hline Corsi 2005 & 67 & 36 & 16 & 64 & 34 & 16 & $2.0 \%$ & $3.00[-21.26,27.26]$ & 2005 & & \\
\hline Caiani 2005 (1) & 96 & 64 & 44 & 99 & 69 & 44 & $1.5 \%$ & $-3.00[-30.81,24.81]$ & 2005 & & \\
\hline Sugeng 2006 & 121 & 85 & 31 & 126 & 96 & 31 & $0.6 \%$ & $-5.00[-50.14,40.14]$ & 2006 & & \\
\hline Krenning 2006 & 96 & 25 & 15 & 99 & 28 & 15 & $3.2 \%$ & $-3.00[-22.00,16.00]$ & 2006 & & - \\
\hline Nikitin 2006 & 121 & 66 & 64 & 117 & 68 & 64 & $2.2 \%$ & $4.00[-19.22,27.22]$ & 2006 & & \\
\hline Chan 2006 & 95 & 48 & 30 & 96 & 54 & 30 & $1.7 \%$ & $-1.00[-26.85,24.85]$ & 2006 & & \\
\hline Jenkins 2006 & 83 & 39 & 110 & 93 & 50 & 110 & $8.3 \%$ & $-10.00[-21.85,1.85]$ & 2006 & - & \\
\hline Jenkins 2007 (2) & 80 & 33 & 30 & 87 & 49 & 30 & $2.6 \%$ & $-7.00[-28.14,14.14]$ & 2007 & & - \\
\hline Jenkins 2007 (1) & 91 & 38 & 50 & 99 & 51 & 50 & $3.8 \%$ & $-8.00[-25.63,9.63]$ & 2007 & & - \\
\hline Qi 2007 & 64.3 & 46.8 & 58 & 79.75 & 57.26 & 58 & $3.2 \%$ & $-15.45[-34.48,3.58]$ & 2007 & & \\
\hline Krenning 2007 & 116 & 58 & 39 & 125 & 69 & 39 & $1.5 \%$ & $-9.00[-37.29,19.29]$ & 2007 & & - \\
\hline Soliman 2007 & 69 & 48 & 53 & 74 & 51 & 53 & $3.3 \%$ & $-5.00[-23.86,13.86]$ & 2007 & & - \\
\hline Soliman 2008 & 122 & 69 & 24 & 127 & 61 & 24 & $0.9 \%$ & $-5.00[-41.85,31.85]$ & 2008 & & \\
\hline Pouleur 2008 & 88 & 56 & 83 & 101 & 65 & 83 & $3.4 \%$ & $-13.00[-31.46,5.46]$ & 2008 & & \\
\hline Chukwu 2008 (Normal) & 52.5 & 13.6 & 35 & 54.5 & 15.4 & 35 & $25.2 \%$ & $-2.00[-8.81,4.81]$ & 2008 & & \\
\hline Chukwu 2008 (Post-MI) & 137.5 & 67.4 & 34 & 141.8 & 69.2 & 34 & $1.1 \%$ & $-4.30[-36.77,28.17]$ & 2008 & & \\
\hline Mor-Avi 2008 & 103 & 71 & 92 & 144 & 99 & 92 & $1.9 \%$ & $-41.00[-65.89,-16.11]$ & 2008 & & \\
\hline $\begin{array}{l}\text { Jenkins } 2009 \\
\text { Subtotal }(95 \% \mathrm{CI})\end{array}$ & 100 & 57 & $\begin{array}{r}50 \\
858\end{array}$ & 117 & 71 & $\begin{array}{r}50 \\
858\end{array}$ & $\begin{array}{r}1.8 \% \\
68.2 \%\end{array}$ & $\begin{array}{l}-17.00[-42.24,8.24] \\
-6.27[-10.41,-2.13]\end{array}$ & 2009 & $\Delta$ & \\
\hline \multicolumn{12}{|c|}{$\begin{array}{l}\text { Heterogeneity: } \mathrm{Chi}^{2}=13.22, \mathrm{df}=17(\mathrm{P}=0.72) ; \mathrm{I}^{2}=0 \% \\
\text { Test for overall effect: } \mathrm{Z}=2.97(P=0.003)\end{array}$} \\
\hline \multicolumn{12}{|l|}{$3.2 .3>2009$} \\
\hline Claver 2010 & 60.4 & 32.2 & 43 & 66.5 & 39.3 & 43 & $5.1 \%$ & $-6.10[-21.29,9.09]$ & 2010 & & \\
\hline Greupner 2012 & 52.6 & 48.4 & 36 & 65.6 & 61.9 & 36 & $1.8 \%$ & $-13.00[-38.67,12.67]$ & 2012 & & - \\
\hline $\begin{array}{l}\text { Coon } 2012 \\
\text { Subtotal }(95 \% \mathrm{Cl})\end{array}$ & 122 & 48 & $\begin{array}{l}18 \\
97\end{array}$ & 137 & 58 & $\begin{array}{l}18 \\
97\end{array}$ & $\begin{array}{l}1.0 \% \\
7.8 \%\end{array}$ & $\begin{array}{r}-15.00[-49.78,19.78] \\
-8.77[-21.00,3.47]\end{array}$ & 2012 & & \\
\hline \multicolumn{12}{|c|}{$\begin{array}{l}\text { Heterogeneity: } \mathrm{Chi}^{2}=0.35, \mathrm{df}=2(P=0.84) ; I^{2}=0 \% \\
\text { Test for overall effect: } Z=1.40(P=0.16)\end{array}$} \\
\hline \multirow{2}{*}{\multicolumn{4}{|c|}{$\begin{array}{l}\text { Heterogeneity: Chi }{ }^{2}=17.72, \mathrm{df}=30(P=0.96) ; I^{2}=0 \% \\
\text { Test for overall effect: } Z=3.72(P=0.0002)\end{array}$}} & & & 1198 & $100.0 \%$ & $-6.49[-9.91,-3.07]$ & & 1 & \\
\hline & & & & & & & & & & $\begin{array}{l}-100-50 \quad 0 \\
\text { MRI Larger }\end{array}$ & Echo Larger \\
\hline
\end{tabular}

tests. This may impact considerably on clinical management of various cardiac conditions, particularly in patients with borderline LV volumes and LVEF values. A better comprehension of their parameter variability between tests may enhance therapeutic decisions. Small studies evaluating echocardiography and CT in comparison to CMR demonstrated controversial results. Greupner $e t a l^{14}$ reported the CT superiority in assessing all three global $\mathrm{LV}$ parameters compared to $2 \mathrm{DE}$, 3DE and ventriculography when CMR values are used as reference standard. Interestingly, 3DE did not perform better than 2DE, in contrast with previous reports and prior meta-analyses. ${ }^{8} \quad 915$ In our study, despite the underestimation of LV volume by 3DE, almost no difference was seen for LVEF when compared to CMR. The underestimation of volumes observed is concordant with the results of two previous meta-analyses ${ }^{8}{ }^{9}$ that evaluated the sources of bias and limits of agreement affecting 3DE. When LV function was considered, there was no difference in bias between 2DE and 3DE, with only a modest difference in variance. ${ }^{8}$ In contrast to these previous studies, we decided to focus on the absolute difference between LV parameters and to exclude the cardiac conditions that markedly alter geometric shape. In fact, the inclusion of major anatomical ventricular alterations (eg, congenital and primary cardiomyopathies) may have influenced prior results, especially when 2DE geometrically based assessments were compared. These former systematic reviews included congenital heart abnormalities in which the global ventricular structure was markedly changed. This may have resulted in an unfair comparison for $2 \mathrm{DE}$ versus 3D modalities considering that congenital diseases represent a significantly reduced proportion of most common everyday clinical practice. Our data confirm that, even excluding limited cardiac diseases in which echocardiography has known limitations, 2DE and 3DE significantly underestimate LV volumes. Although 3DE relies on fewer geometrical assumptions than 2DE and approximately halves the absolute bias of 


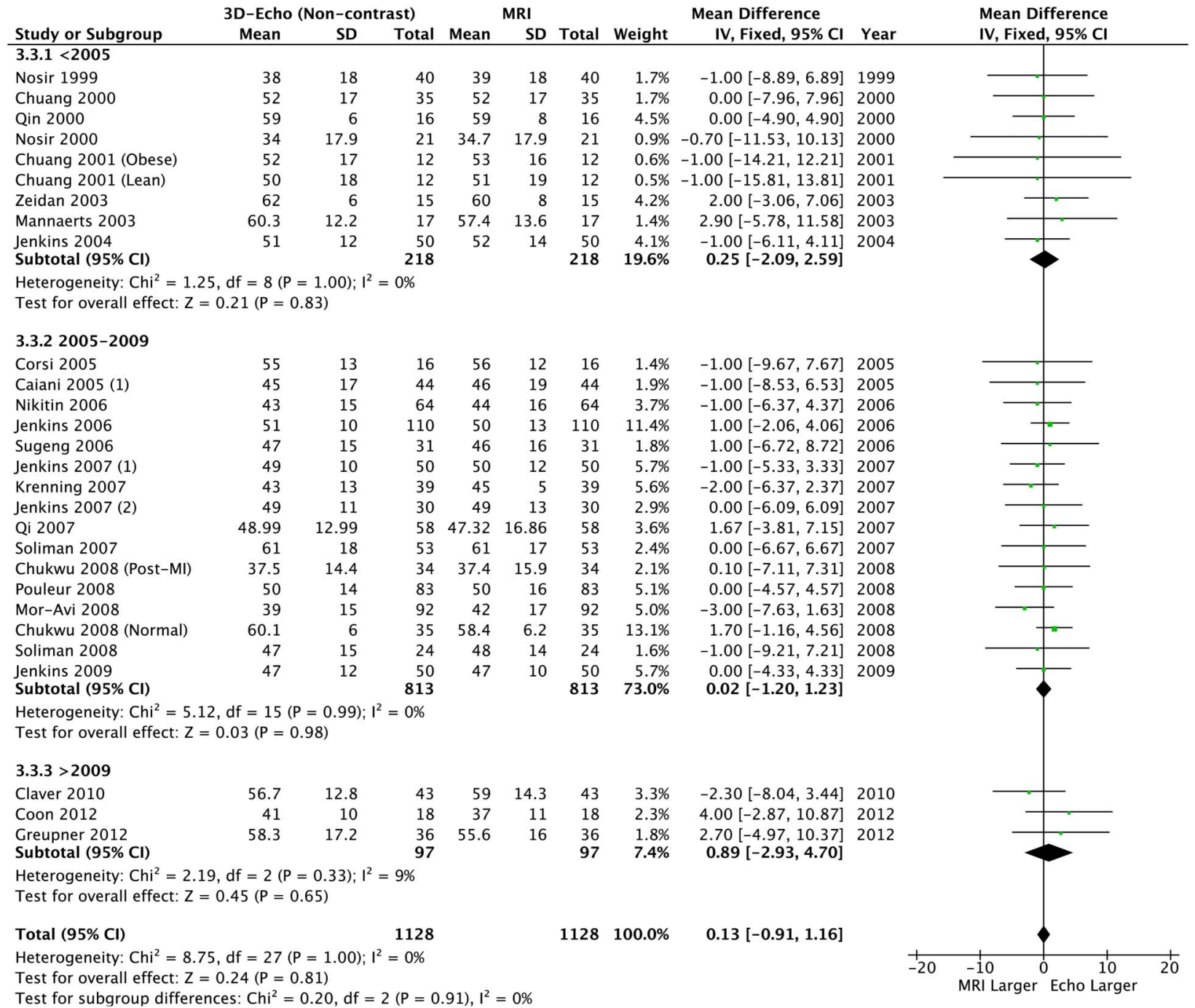

Figure 10 Left ventricular ejection fraction: 3D echo versus CMR. CMR, cardiac MR; 3D, three-dimensional.

underestimation, it still performs worse than CT, compared with CMR. This is probably due to the reduced spatial resolution and consequent lack of precision in distinguishing myocardial trabeculations and endocardial borders. ${ }^{9} 1617$

The highest spatial resolution of CT and its similar 3D reconstruction method to CMR may explain the perfect agreement observed in quantification of volumes. Our results are complementary to two previous systemic reviews comparing CT and CMR, one on older and one on newer generation scanners. ${ }^{18} 19$ These have shown a good agreement for LVEF, but no analysis of LV volumes bias compared to CMR was performed. However, our data suggest that functional evaluation is not as good as echocardiography when compared to CMR. Although CT has the disadvantages of risk radiation and iodinated contrast exposure, it remains a useful method for second-level cardiac anatomical evaluation in those patients with contraindications to MRI (eg, implanted devices, claustrophobia) and its use has more than doubled over the past 10 years. ${ }^{12}$ Possible explanations of the reduced performance in functional assessment should consider the substantial differences in LV assessment between the various imaging modalities. First of all, with the exception of the newest whole-heart 320-slice scanner, CT acquires the cardiac volume in more heartbeats in contrast to echocardiography, by which LV evaluation is performed on a single heart beat acquisition. Furthermore, $\beta$-blockers commonly administered prior to cardiovascular and coronary CT scans to lower heart rate and limit cardiac motion-related artefacts, may directly affect the evaluation of LV function. Finally, most studies evaluating 2DE and 3DE have commonly excluded patients with poor echocardiographic views, leading to an overestimation of echocardiographic accuracy compared to routine practice. When good images are available, 3DE improves the accuracy and reproducibility of $\mathrm{LV}$ volume and $\mathrm{EF}$ measurements overall. $^{20}$

In addition to these considerations, although CMR is the gold standard for LV quantification, there still are significant limitations in LV quantification when comparing 


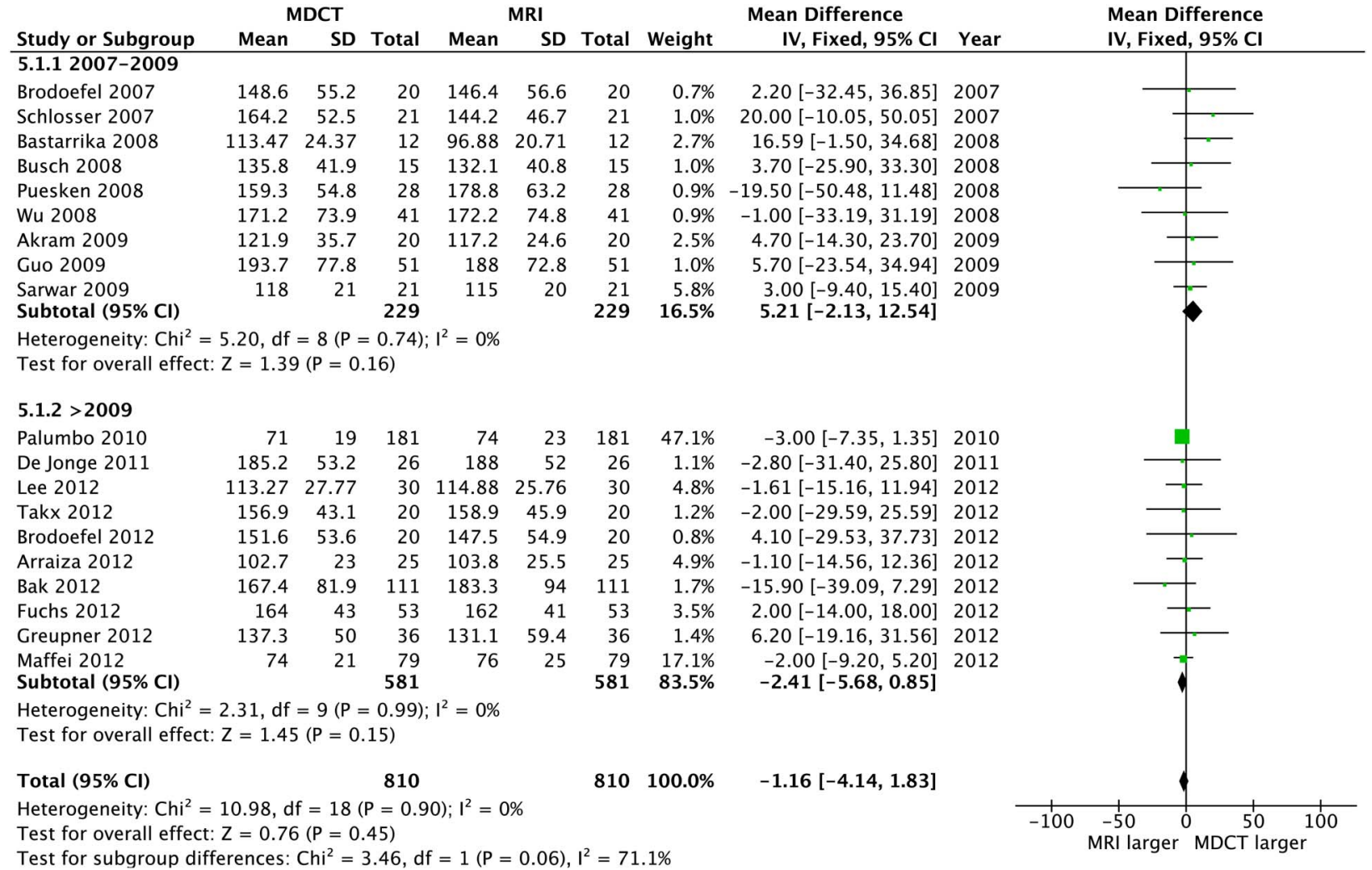

Figure 11 Left ventricular end-diastolic volume: CT versus CMR. CMR, cardiac MR.

\begin{tabular}{|c|c|c|c|c|c|c|c|c|c|c|c|c|}
\hline \multirow{3}{*}{$\frac{\text { Study or Subgroup }}{5.2 .12007-2009}$} & \multicolumn{3}{|c|}{ MDCT } & \multicolumn{3}{|c|}{ MRI } & \multicolumn{3}{|c|}{ Mean Difference } & \multirow{2}{*}{\multicolumn{3}{|c|}{$\begin{array}{l}\text { Mean Difference } \\
\text { IV, Fixed, } 95 \% \mathrm{CI}\end{array}$}} \\
\hline & Mean & SD & Total & Mean & SD & Total & Weight & IV, Fixed, 95\% CI & Year & & & \\
\hline & & & & & & & & & & & & \\
\hline Schlosser 2007 & 77.3 & 46.6 & 21 & 63.8 & 47.3 & 21 & $0.7 \%$ & $13.50[-14.90,41.90]$ & 2007 & & & \\
\hline Brodoefel 2007 & 70.5 & 35.2 & 20 & 69.1 & 35.8 & 20 & $1.1 \%$ & $1.40[-20.60,23.40]$ & 2007 & & & \\
\hline Bastarrika 2008 & 35.43 & 6.42 & 12 & 30.49 & 6.82 & 12 & $18.7 \%$ & $4.94[-0.36,10.24]$ & 2008 & & & 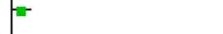 \\
\hline Puesken 2008 & 71.8 & 47.8 & 28 & 82.5 & 56.4 & 28 & $0.7 \%$ & $-10.70[-38.08,16.68]$ & 2008 & & & \\
\hline Wu 2008 & 94.8 & 68.3 & 41 & 93.9 & 68.7 & 41 & $0.6 \%$ & $0.90[-28.75,30.55]$ & 2008 & & & \\
\hline Busch 2008 & 54.9 & 29.6 & 15 & 57.6 & 27.3 & 15 & $1.3 \%$ & $-2.70[-23.08,17.68]$ & 2008 & & & \\
\hline Akram 2009 & 42.5 & 16.6 & 20 & 42.5 & 14.6 & 20 & $5.6 \%$ & $0.00[-9.69,9.69]$ & 2009 & & & \\
\hline Sarwar 2009 & 51 & 15 & 21 & 51 & 15 & 21 & $6.4 \%$ & $0.00[-9.07,9.07]$ & 2009 & & & \\
\hline $\begin{array}{l}\text { Guo } 2009 \\
\text { Subtotal }(95 \% \mathrm{Cl})\end{array}$ & 94.5 & 44.3 & $\begin{array}{r}51 \\
229\end{array}$ & 92.9 & 42 & $\begin{array}{r}51 \\
229\end{array}$ & $\begin{array}{r}1.9 \% \\
36.8 \%\end{array}$ & $\begin{array}{r}1.60[-15.15,18.35] \\
2.59[-1.19,6.36]\end{array}$ & 2009 & & & 1 \\
\hline \multicolumn{13}{|c|}{$\begin{array}{l}\text { Heterogeneity: } \mathrm{Chi}^{2}=3.11, \mathrm{df}=8(P=0.93) ; \mathrm{I}^{2}=0 \% \\
\text { Test for overall effect: } Z=1.34(P=0.18)\end{array}$} \\
\hline \multicolumn{13}{|l|}{$5.2 .2>2009$} \\
\hline Palumbo 2010 & 35 & 18 & 181 & 36 & 22 & 181 & $30.6 \%$ & $-1.00[-5.14,3.14]$ & 2010 & & & \\
\hline De Jonge 2011 & 74.2 & 25 & 26 & 81 & 27 & 26 & $2.6 \%$ & $-6.80[-20.94,7.34]$ & 2011 & & & \\
\hline Maffei 2012 & 37 & 19 & 79 & 38 & 23 & 79 & $12.1 \%$ & $-1.00[-7.58,5.58]$ & 2012 & & & \\
\hline Takx 2012 & 66.4 & 42.8 & 20 & 60.7 & 45.7 & 20 & $0.7 \%$ & $5.70[-21.74,33.14]$ & 2012 & & & \\
\hline Arraiza 2012 & 37.9 & 19 & 25 & 36.7 & 18.5 & 25 & $4.9 \%$ & $1.20[-9.20,11.60]$ & 2012 & & & \\
\hline Bak 2012 & 60.2 & 49.4 & 111 & 67.4 & 49.4 & 111 & $3.1 \%$ & $-7.20[-20.20,5.80]$ & 2012 & & & \\
\hline Greupner 2012 & 65.7 & 51.7 & 36 & 65.6 & 61.9 & 36 & $0.8 \%$ & $0.10[-26.25,26.45]$ & 2012 & & & \\
\hline Fuchs 2012 & 66 & 36 & 53 & 74 & 34 & 53 & $3.0 \%$ & $-8.00[-21.33,5.33]$ & 2012 & & & \\
\hline Brodoefel 2012 & 69.2 & 32.7 & 20 & 67.5 & 32.9 & 20 & $1.3 \%$ & $1.70[-18.63,22.03]$ & 2012 & & & \\
\hline $\begin{array}{l}\text { Lee } 2012 \\
\text { Subtotal }(95 \% \mathrm{Cl})\end{array}$ & 42.86 & 22.57 & $\begin{array}{r}30 \\
581\end{array}$ & 45.61 & 21.9 & $\begin{array}{r}30 \\
581\end{array}$ & $\begin{array}{r}4.1 \% \\
63.2 \%\end{array}$ & $\begin{array}{r}-2.75[-14.00,8.50] \\
-1.68[-4.56,1.21]\end{array}$ & 2012 & & & \\
\hline \multicolumn{13}{|c|}{$\begin{array}{l}\text { Heterogeneity: } \mathrm{Chi}^{2}=2.94, \mathrm{df}=9(\mathrm{P}=0.97) ; \mathrm{I}^{2}=0 \% \\
\text { Test for overall effect: } Z=1.14(P=0.25)\end{array}$} \\
\hline Total $(95 \% \mathrm{Cl})$ & & & 810 & & & 810 & $100.0 \%$ & $-0.11[-2.40,2.18]$ & & & & \\
\hline \multicolumn{7}{|c|}{$\begin{array}{l}\text { Heterogeneity: } \mathrm{Chi}^{2}=9.14, \mathrm{df}=18(\mathrm{P}=0.9 \\
\text { Test for overall effect: } \mathrm{Z}=0.09(\mathrm{P}=0.93) \\
\text { Test for subgroup differences: } \mathrm{Chi}^{2}=3.10, \mathrm{~d}\end{array}$} & 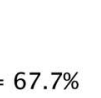 & & & -100 & $\begin{array}{l}-50 \\
\text { MRI larger }\end{array}$ & $\begin{array}{lll} & 1 & 10 \\
0 & 100\end{array}$ \\
\hline
\end{tabular}

Figure 12 Left ventricular end-systolic volume: CT versus CMR. CMR, cardiac MR. 


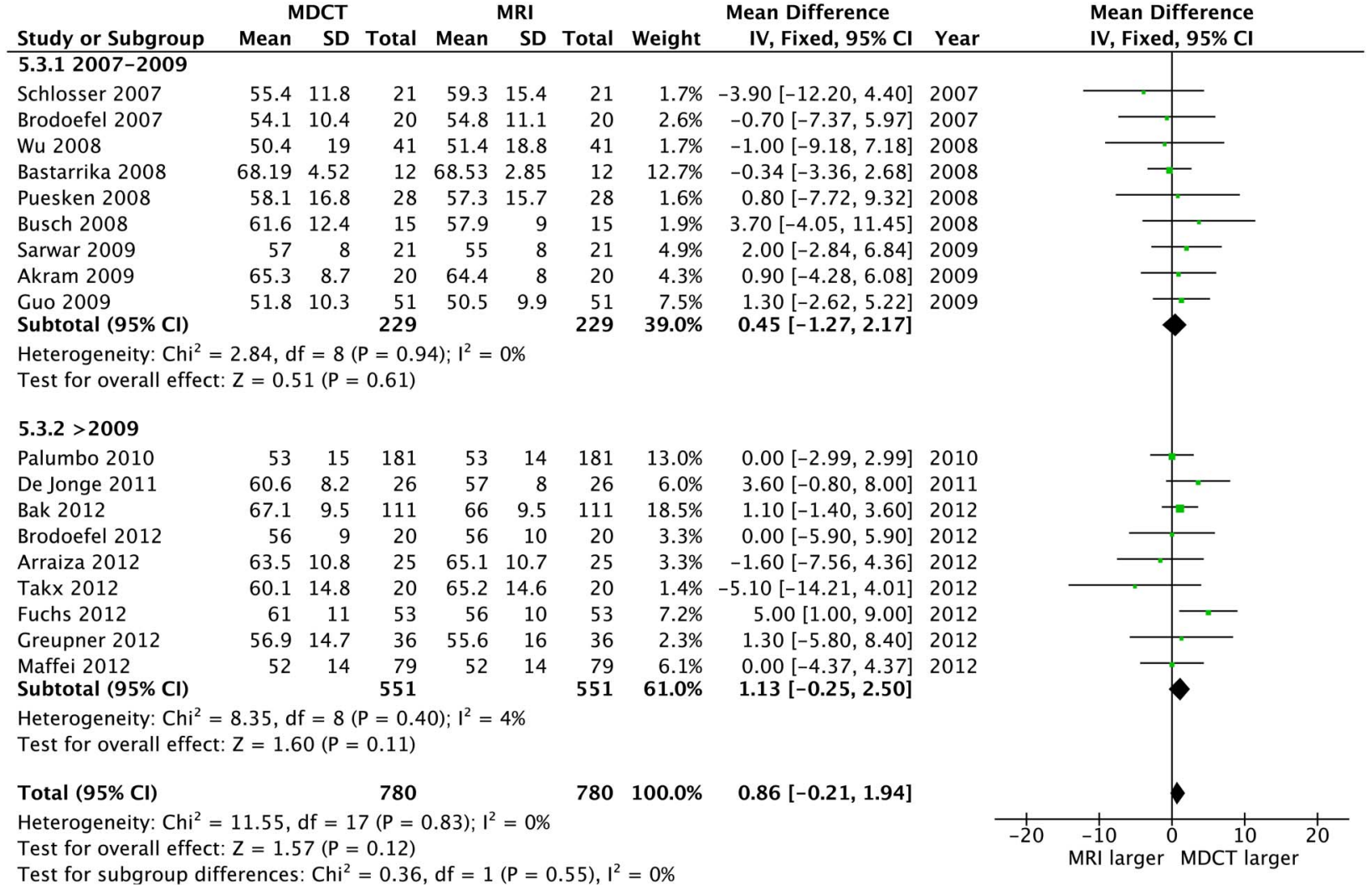

Figure 13 Left ventricular ejection fraction: $\mathrm{CT}$ versus $\mathrm{CMR}$. CMR, cardiac MR.

imaging techniques by setting CMR parameters as true values for bias estimation, such as basal slice selection and multiple breath-holds acquisition. Moreover, most clinical studies, and indeed clinical practice, are based on echocardiographic parameters, and 2DE cut-offs for EF are the most often reported and relied on. ${ }^{21-23}$ Although CMR parameters are compared to well-established normality databases, ${ }^{24} 25$ the data on patient management and outcome based on CMR are still limited. However, up to date CMR remains the highest reproducible LV quantification modality. ${ }^{26}$ Technical advances are allowing better semiautomatic acquisition and analysis for higher operator independency, ${ }^{27} 28$ and direct prognostic evidence with CMR is growing. ${ }^{29} 30$

\section{Limitations}

The majority of studies included a small number of patients with different baseline characteristics. Most of the studies analysed were single-centre retrospective trials, and, therefore, issues of potential referral bias and inconsistent data collection may be present. As in any meta-analysis, the validity of our results is dependent on the validity of the studies included but this variability reflects clinical practice. There are multiple risks of bias in systematic reviews; however, our funnel plot analyses mostly demonstrated no significant publication bias for the results without significant heterogeneity, except for 2DE. A few studies had to be excluded due to different numbers of patients undergoing different modalities. Technical issues in completing the scans mainly caused this inconsistency. We excluded these studies to keep the balance between the modality groups. Some studies did not report LVEF but only presented volumes. We chose to include these since the analyses for LV volumes and LVEF were performed separately and consequently we considered them as independent parameters. We did restrict inclusion of the CT studies to recent technology only, and did not do this for the echo studies. The advances in CT imaging over this time period have been substantial, and more so than echo. Nevertheless, in the analyses, we have subgrouped the studies by year of publication to partially account for this, and no chronological impact is apparent.

\section{Conclusion}

Comparing commonly available non-invasive imaging modalities to CMR as a reference standard, 3DE holds the highest accuracy in LVEF estimation, although 2DE and 3DE-derived LV volumes are significantly underestimated. Newer generation CT shows excellent accuracy for LV volumes quantification. These results may help clinicians to better understand the degree of absolute bias between different cardiac imaging modalities and may have potential implications for patient follow-up and management.

Author affiliations

${ }^{1}$ Awhina Health Campus, Waitemata District Health Board, Auckland, New Zealand 
${ }^{2}$ Department of Medicine, Section of Cardiology, University of Verona, Verona, Italy

${ }^{3}$ Institute of Diagnostic Ultrasound, Australasian Sonographers Association, Melbourne, Victoria, Australia

\section{Twitter Follow Gillian Whalley at @GWhalleyPhD}

Acknowledgements The authors thank the following people for providing additional data or confirming the data we had extracted from their studies: $\mathrm{Dr}$ Antonio Abbate, Dr Michael Chuang, Dr Ana Garcia-Alvarez, Dr Ola Gjessdal, Dr Sigrun Halvorsen, Dr Carly Jenkins, Dr Jens Kastrup, Dr Bernhard Metzler, Dr Masaaki Takeuchi, Dr Victor Mor-Avi, Dr Jürgan Scharhag, Dr Marta Sitges, Dr Osama Soliman, Dr Stefan Steorck and Dr Cezary Szmigielski.

Contributors MR and SA conducted the searches. All four authors developed the search strategy. MR drafted the first manuscript, and SA, GAW and JPC offered feedback and edited the final version. All the authors contributed to the design and conduct of the study and have approved this final version.

Funding This study was funded by Awhina Knowledge and Innovation Centre, Waitemata District Health Board (summer studentship).

\section{Competing interests None declared.}

Provenance and peer review Not commissioned; externally peer reviewed.

Data sharing statement Our data are limited to the group level data for the individual studies we used. Some of these were easily, and some not so easily, accessible. We would be happy to share our data.

Open Access This is an Open Access article distributed in accordance with the Creative Commons Attribution Non Commercial (CC BY-NC 4.0) license, which permits others to distribute, remix, adapt, build upon this work noncommercially, and license their derivative works on different terms, provided the original work is properly cited and the use is non-commercial. See: http:// creativecommons.org/licenses/by-nc/4.0/

\section{REFERENCES}

1. Priori SG, Blomstrom-Lundqvist C, Mazzanti A, et al. 2015 ESC Guidelines for the management of patients with ventricular arrhythmias and the prevention of sudden cardiac death: the Task Force for the Management of Patients with Ventricular Arrhythmias and the Prevention of Sudden Cardiac Death of the European Society of Cardiology (ESC) Endorsed by: Association for European Paediatric and Congenital Cardiology (AEPC). Eur Heart $J$ 2015;36:2793-867.

2. Nishimura RA, Otto CM, Bonow RO, et al. 2014 AHA/ACC Guideline for the Management of Patients With Valvular Heart Disease: a report of the American College of Cardiology/American Heart Association Task Force on Practice Guidelines. Circulation 2014;129:e521-643.

3. McMurray JJ, Adamopoulos S, Anker SD, et al. ESC Guidelines for the diagnosis and treatment of acute and chronic heart failure 2012 the Task Force for the Diagnosis and Treatment of Acute and Chronic Heart Failure 2012 of the European Society of Cardiology. Developed in collaboration with the Heart Failure Association (HFA) of the ESC. Eur Heart J 2012;33:1787-847.

4. Taylor GJ, Humphries JO, Mellits ED, et al. Predictors of clinical course, coronary anatomy and left ventricular function after recovery from acute myocardial infarction. Circulation 1980;62:960-70.

5. White HD, Norris RM, Brown MA, et al. Left ventricular end-systolic volume as the major determinant of survival after recovery from myocardial infarction. Circulation 1987;76:44-51.

6. Hundley WG, Bluemke DA, Finn JP, et al. ACCF/ACR/AHA/NASCI/ SCMR 2010 expert consensus document on cardiovascular magnetic resonance: a report of the American College of Cardiology Foundation Task Force on Expert Consensus Documents. Circulation 2010;121:2462-508.

7. Bellenger NG, Burgess MI, Ray SG, et al. Comparison of left ventricular ejection fraction and volumes in heart failure by echocardiography, radionuclide ventriculography and cardiovascular magnetic resonance; are they interchangeable? Eur Heart $J$ 2000;21:1387-96.

8. Dorosz JL, Lezotte DC, Weitzenkamp DA, et al. Performance of 3-dimensional echocardiography in measuring left ventricular volumes and ejection fraction: a systematic review and meta-analysis. J Am Coll Cardiol 2012;59:1799-808.

9. Shimada YJ, Shiota T. A meta-analysis and investigation for the source of bias of left ventricular volumes and function by three-dimensional echocardiography in comparison with magnetic resonance imaging. Am J Cardiol 2011;107:126-38.

10. Jenkins C, Bricknell K, Hanekom L, et al. Reproducibility and accuracy of echocardiographic measurements of left ventricular parameters using real-time three-dimensional echocardiography. J Am Coll Cardiol 2004:44:878-86.

11. Taylor AJ, Cerqueira M, Hodgson JM, et al. ACCF/SCCT/ACR/AHA/ ASE/ASNC/NASCI/SCAI/SCMR 2010 Appropriate Use Criteria for Cardiac Computed Tomography. A Report of the American College of Cardiology Foundation Appropriate Use Criteria Task Force, the Society of Cardiovascular Computed Tomography, the American College of Radiology, the American Heart Association, the American Society of Echocardiography, the American Society of Nuclear Cardiology, the North American Society for Cardiovascular Imaging, the Society for Cardiovascular Angiography and Interventions, and the Society for Cardiovascular Magnetic Resonance. J Cardiovasc Comput Tomogr 2010;4:407.e1-33.

12. Halliburton SS, Abbara S, Chen MY, et al. SCCT guidelines on radiation dose and dose-optimization strategies in cardiovascular CT. J Cardiovasc Comput Tomogr 2011;5:198-224.

13. Achenbach S, Marwan M, Ropers D, et al. Coronary computed tomography angiography with a consistent dose below $1 \mathrm{mSv}$ using prospectively electrocardiogram-triggered high-pitch spiral acquisition. Eur Heart J 2010;31:340-6.

14. Greupner J, Zimmermann E, Grohmann A, et al. Head-to-head comparison of left ventricular function assessment with 64-row computed tomography, biplane left cineventriculography, and both 2- and 3-dimensional transthoracic echocardiography: comparison with magnetic resonance imaging as the reference standard. J Am Coll Cardiol 2012:59:1897-907.

15. Jenkins C, Moir S, Chan J, et al. Left ventricular volume measurement with echocardiography: a comparison of left ventricular opacification, three-dimensional echocardiography, or both with magnetic resonance imaging. Eur Heart J 2009;30:98-106.

16. Chukwu EO, Barasch E, Mihalatos DG, et al. Relative importance of errors in left ventricular quantitation by two-dimensional echocardiography: insights from three-dimensional echocardiography and cardiac magnetic resonance imaging. J Am Soc Echocardiogr 2008;21:990-7.

17. Mor-Avi V, Jenkins C, Kuhl HP, et al. Real-time 3-dimensional echocardiographic quantification of left ventricular volumes: multicenter study for validation with magnetic resonance imaging and investigation of sources of error. JACC Cardiovasc Imaging 2008:1:413-23.

18. Asferg C, Usinger L, Kristensen TS, et al. Accuracy of multi-slice computed tomography for measurement of left ventricular ejection fraction compared with cardiac magnetic resonance imaging and two-dimensional transthoracic echocardiography: a systematic review and meta-analysis. Eur J Radiol 2012;81:e757-62.

19. Van der Vleuten PA, Willems TP, Gotte MJ, et al. Quantification of global left ventricular function: comparison of multidetector computed tomography and magnetic resonance imaging. A meta-analysis and review of the current literature. Acta Radiol 2006;47:1049-57.

20. Ruddox V, Mathisenc M, Bækkevarb M, et al. Is 3D echocardiography superior to $2 \mathrm{D}$ echocardiography in general practice? A systematic review of studies published between 2007 and 2012. Int J Cardiol 2013;168:1306-15.

21. Bardy GH, Lee KL, Mark DB, et al. Amiodarone or an implantable cardioverter-defibrillator for congestive heart failure. $N$ Engl J Med 2005;352:225-37.

22. Moss AJ, Hall WJ, Cannom DS, et al. Improved survival with an implanted defibrillator in patients with coronary disease at high risk for ventricular arrhythmia. Multicenter Automatic Defibrillator Implantation Trial Investigators. N Engl J Med 1996;335:1933-40.

23. Moss AJ, Hall WJ, Cannom DS, et al. Cardiac-resynchronization therapy for the prevention of heart-failure events. $N$ Engl J Med 2009;361:1329-38.

24. Hudsmith LE, Petersen SE, Francis JM, et al. Normal human left and right ventricular and left atrial dimensions using steady state free precession magnetic resonance imaging. $J$ Cardiovasc Magn Reson 2005;7:775-82.

25. Maceira AM, Prasad SK, Khan M, et al. Normalized left ventricular systolic and diastolic function by steady state free precession cardiovascular magnetic resonance. J Cardiovasc Magn Reson 2006;8:417-26.

26. Danilouchkine MG, Westenberg JJ, de Roos A, et al. Operator induced variability in cardiovascular MR: left ventricular 
measurements and their reproducibility. J Cardiovasc Magn Reson 2005;7:447-57.

27. Nassenstein $K$, de Greiff $A$, Hunold P. MR evaluation of left ventricular volumes and function: threshold-based $3 \mathrm{D}$ segmentation versus short-axis planimetry. Invest Radiol 2009;44:635-40.

28. Lelieveldt BP, van der Geest RJ, Lamb HJ, et al. Automated observer-independent acquisition of cardiac short-axis MR images: a pilot study. Radiology 2001;221:537-42.
29. Bluemke DA, Kronmal RA, Lima JA, et al. The relationship of left ventricular mass and geometry to incident cardiovascular events: the MESA (Multi-Ethnic Study of Atherosclerosis) study. J Am Coll Cardiol 2008;52:2148-55.

30. Gulati A, Ismail TF, Jabbour A, et al. The prevalence and prognostic significance of right ventricular systolic dysfunction in nonischemic dilated cardiomyopathy. Circulation 2013;128:1623-33. 